\title{
Walking Upright: An Actor's Blueprint of Process and Character Development in Exit, Pursued by a Bear by Lauren Gunderson
}

Imani R. Berry

Follow this and additional works at: https://researchrepository.wvu.edu/etd

Part of the Acting Commons

\section{Recommended Citation}

Berry, Imani R., "Walking Upright: An Actor's Blueprint of Process and Character Development in Exit, Pursued by a Bear by Lauren Gunderson" (2018). Graduate Theses, Dissertations, and Problem Reports. 5195.

https://researchrepository.wvu.edu/etd/5195

This Dissertation is protected by copyright and/or related rights. It has been brought to you by the The Research Repository @ WVU with permission from the rights-holder(s). You are free to use this Dissertation in any way that is permitted by the copyright and related rights legislation that applies to your use. For other uses you must obtain permission from the rights-holder(s) directly, unless additional rights are indicated by a Creative Commons license in the record and/ or on the work itself. This Dissertation has been accepted for inclusion in WVU Graduate Theses, Dissertations, and Problem Reports collection by an authorized administrator of The Research Repository @ WVU.

For more information, please contact researchrepository@mail.wvu.edu. 


\title{
Walking Upright: \\ An Actor's Blueprint of Process and Character Development in Exit, Pursued by a Bear by Lauren Gunderson
}

\author{
Imani R. Berry
}

Thesis submitted

to the College of Creative Arts

at West Virginia University

in partial fulfillment of the requirements for the degree of

Master of Fine Arts in

Acting

\author{
Radhica Ganapathy, Ph.D., Chair \\ Irene Alby, MFA \\ Lee Blair, MFA \\ Jerry McGonigle, MFA
}

School of Theatre and Dance
Morgantown, West Virginia 2018

[Aristotle, character development, Bertolt Brecht, Michael Chekhov, Uta Hagen, Sanford Meisner, Lee Strasberg, Epic theatre]

Copyright 2018 [Imani R. Berry] 


\section{ABSTRACT \\ Walking Upright: \\ An Actor's Blueprint of Process and Character Development in Exit, Pursued by a Bear by Lauren Gunderson}

\section{Imani R. Berry}

To execute the demands of a play the actor must sift through an overwhelming amount of material on the play's style, period, and given circumstances; as well as their own physical, vocal, and emotional life that ultimately affect their ability to access character and performance. This paper will investigate the stumbling blocks an actor faces when creating a role, and how the actor's enquiries culminate into a performance. It provides a detailed account of research, rehearsals, and performance study that were embarked on when creating the role of NAN in Lauren Gunderson's Exit, Pursued By a Bear.

The actor's process is a collaborative effort; it is influenced by parties outside of his or her research such as the playwright, director and text. To adequately examine this process, and these external factors, this document is divided into the following chapters: Playwright, Director, Text Analysis, Actor's Process, and Performance \& Reflection. It discusses the use of the following acting methodologies: Michael Chekhov, Sanford Meisner, Lee Strasberg and Uta Hagen. There is additional investigation of the demands placed on the actor's instrument such as the voice, imagination, and body. Solutions to these demands are explored using the work of Kristin Linklater, Patsy Rodenburg, and Jackie Snow. 


\section{ACKNOWLEDGEMENTS}

I would like to acknowledge the faculty and staff of West Virginia University for their guidance, leadership, and patience throughout my matriculation as a W.E.B. Du Bois Graduate Fellow. I have been supported by numerous departments on campus and would like to apologize for anyone that goes unnamed here. Please charge it to the overwhelming nature of this document and not my heart; those that are listed are presented in no particular order.

Dr. Radhica Ganapathy, thank you for spearheading the ship and pushing me beyond what I thought was possible in the writing of this document. I admire your knowledge and I am grateful for your compassion and generosity.

Thank you to the remaining members of my committee; you each gave your time, support, valuable feedback, and provided insight during this process. I am grateful to my director, Professor Irene Alby, from whom I learned tremendously during the process of Exit, Pursued by a Bear. Thank you for trusting me with the role of NAN, and for instilling principles in me that have changed me as an artist and human. This would not have been possible without the help of Professor Lee Blair. Thank you for that callback three years ago! Who would have thought it would culminate into this? You have encouraged me along my journey and always keep me laughing. I would especially like to thank Professor Jerry McGonigle, my advisor, and one of the key recruiters in my application to the School of Theatre \& Dance. You have always been there to support and push me. I am grateful for every encouraging word, challenge, and letter of recommendation.

I am grateful to my professors over the past three years who have each affected me in special and unique ways. I am glad we shared this moment in time Professor Jessica Bishop, 
Professor Laura Hitt, Professor Cathy O’Dell, Dr. Jules Malarcher, Professor Mary McClung, and Professor Cornel Gabara.

Thank you to Dr. Paul Kreider, Dr. John Hendricks, Dr. Keith Jackson, and Professor Joshua Williamson; I am grateful for your investment in me during my matriculation at the College of Creative Arts.

Additionally, I would like to thank my classmates (we did it!): Professor General Hambrick, Dr. Robert Chafin, Dr. James Mitchell, RJ Nestor, Dr. Constinia Charbonnette, Dr. Jacob Sanwidi, Dr. Katherine Karraker, WVU's Office of Graduate Education \& Life (OGEL), WVU's Black Graduate Student Association (BGSA), Marjorie Fuller, Eric Jordan, and Andrea Teeman.

Finally, I would like to thank my phenomenal, unwavering family. You each mean the absolute world to me. I could not get through the day, nonetheless this document, or the past three years without your love and support. I am forever indebted to my tribe: Granny, Mama, De, my loving husband, Brandon, and my bother, Nate. 


\section{Table of Contents}

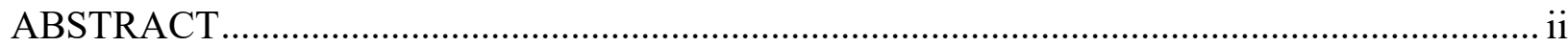

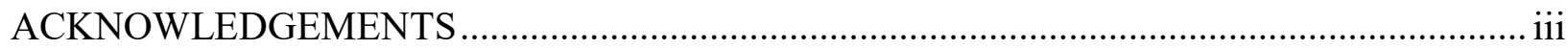

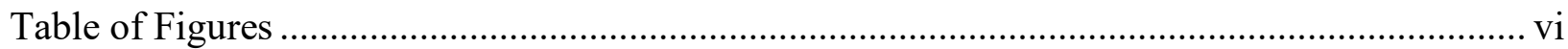

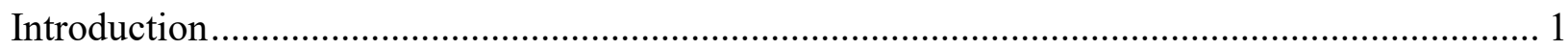

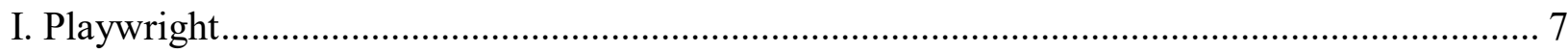

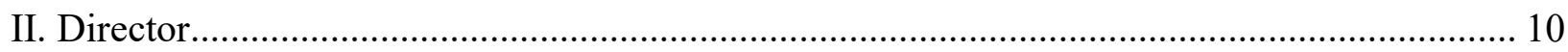

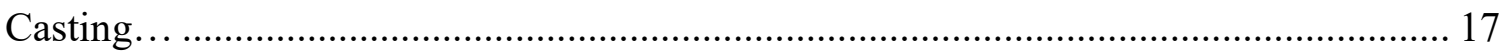

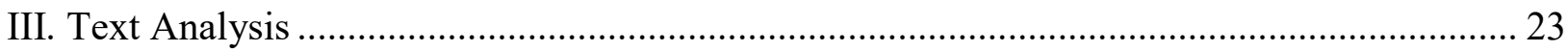

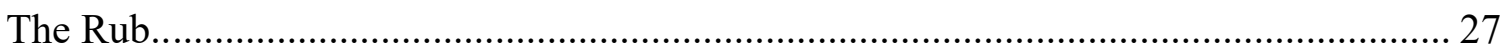

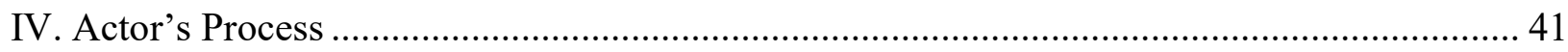

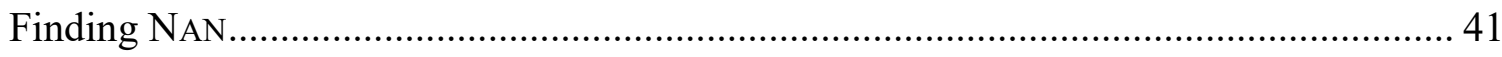

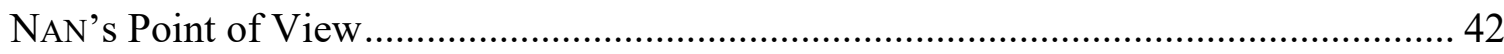

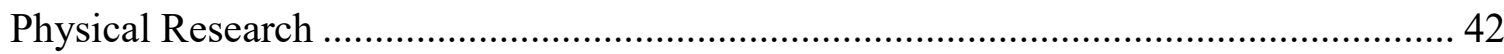

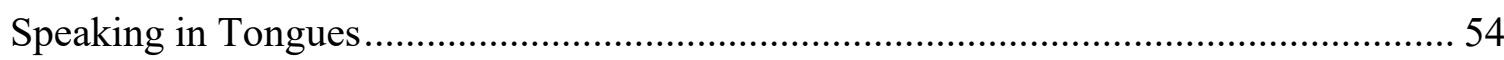

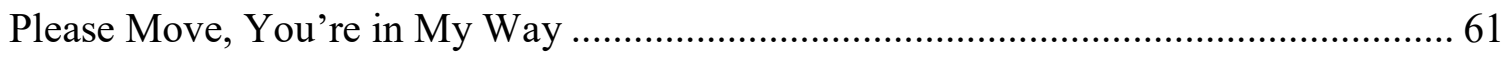

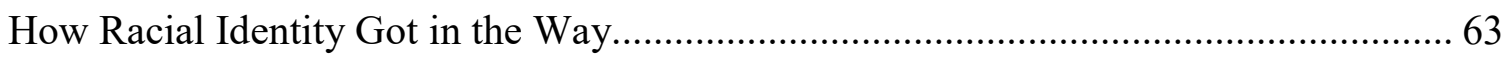

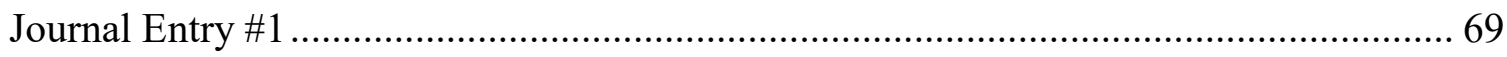

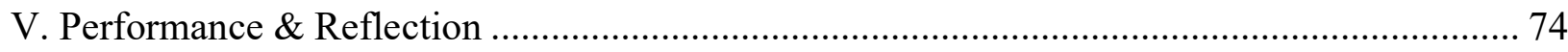

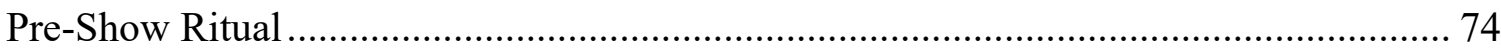

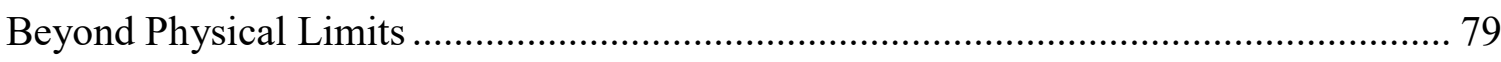

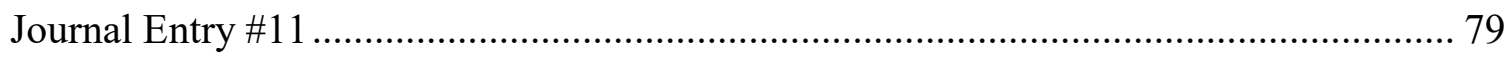

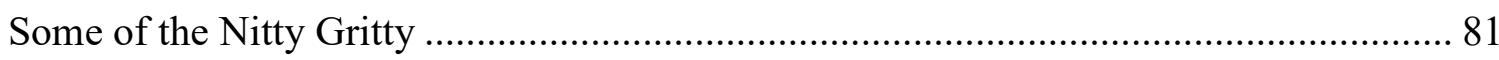

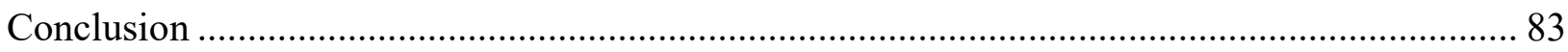

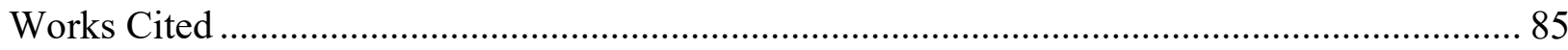




\section{Table of Figures}

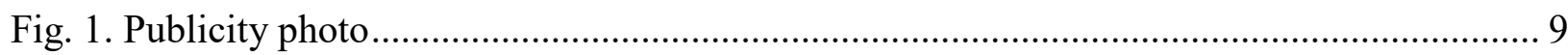

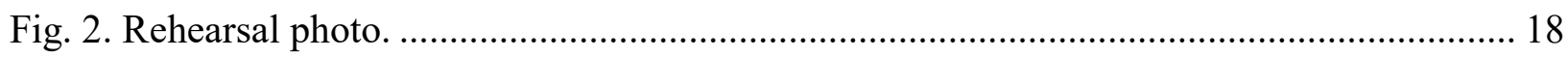

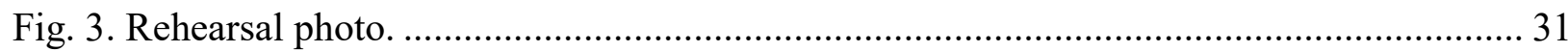

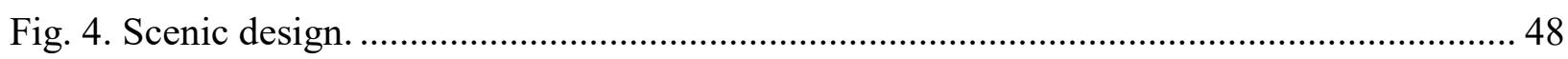

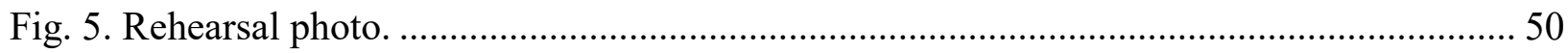

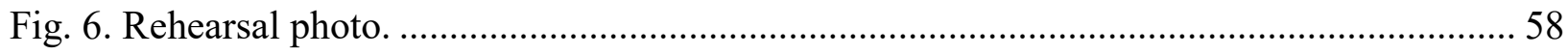

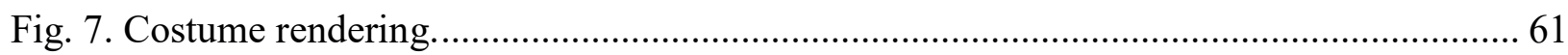

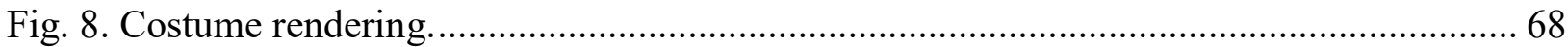




\section{Introduction}

An actor is charged with the task of creating human beings; the opportunity to live multiple lives in one lifetime. It isn't enough for an actor to "perform," their idea of a character in a fictitious world, but these persons should extend beyond the page. What results is a threedimensional human being, something more than lifting a character off the page like a paper cut out, but a friend, an inspiration, or, God forbid, an image of ourselves that moves our audience. In order to reach that catharsis in the spectator ${ }^{1}$, the change within ourselves that each character demands, the actor must research, investigate, and uncover as meticulously as a scientist. In doing so the actor will define the character's point of view, back story, wants, and desires; as well as find those links that connect their reality with the playwright's fictitiously constructed world. His/her research is complete once the artists is able to walk through the threshold of the wings and simply—be. Living, breathing, reacting, playing, and doing, without the encroaching judgment of the conscious mind.

These are ideals. They are the result of the perfect incubation of time to fashion character, explore the character's qualms and ticks; yet unlike science, the arts are not afforded the luxury of trials, or drawn out experiments to achieve an ideal solution. The literary performing arts, more than other artistic mediums, are expected to generate viable, commercial product quickly. Musicians are given time to mull over melodies, construct them, then deconstruct. Visual arts are given solace to birth their next Basquiat. Dancers study choreography intensely, and each fall from a grand jeté maintains its beauty because the audience recognizes their own physical limitations incapable of such skill. Audiences are awed at an actor's ability to memorize lines,

\footnotetext{
${ }^{1}$ A term developed by Bertolt Brecht to name the audience. This label was founded on the belief that the audience should be actively involved in the play beyond entertainment; instead the theatre should cultivate social activists motivated for change in our collective society (Cash).
} 
but what is void from understanding the actor's process is their dual responsibilities as both scholar and artist. To execute the demands of a play, the actor must sift through overwhelming materials on the play's style, period, and circumstances; as well as their own physical, vocal, and emotional life that ultimately affect their access to the character and performance. These demands, and lack of time, most professionals receive four weeks of rehearsals before their first preview, can force actors into self-conscious frenzies that block their ability to do the work. This paper will investigate the stumbling blocks actors face when creating a role, and how the actor's enquiries culminate into a performance. Additionally, the paper will present research outside of the character development process that directly and indirectly affects the actor's final product. These influences are the playwright, director, text analysis, and actor's process. As an actor gains experience his/her methods will alter based on their analysis of their performance through reflection. To create a cohesive discovery of those influences this paper will progress through the following chapters as follows.

\section{Chapter One: Playwright}

The playwright is the absent puppeteer. He or she drafts alone, or in community, the roadmap that informs the actor of their character's needs, wants, and desires. Plays are intended to reflect three dimensional worlds, you and me right now, or you and me back then, but they are merely snapshots of a moment, or a series of moments in time. They are not fluid, or even cohesive at times. These snap shots provide evidence of the urgent need in the character that must be tackled right now. All the information that leads to this moment cannot be addressed in the play, if it were, scenes of exposition would linger endlessly and tirelessly. We can all accept that each day in our lives is not as exciting as the next, or previous one. Therefore, plays are incomplete maps, there is always missing information, clues the puppeteer has neglected, or chosen to not provide 
for the lack of time, or sake of the craft. This void of knowledge manifests a gap in understanding the character themselves and given circumstances ${ }^{2}$. To clear this hurdle, the actor must generate a backstory for the missing information.

In addition, all playwrights have a style, while they may function within the same genre i.e. Chekhov vs. Ibsen in Realism, their styles differ. The playwright writes within the genre that either most reflects their cultural context, or the one which inspires them. Because the art form of theatre is hundreds of years old, the contemporary playwright of today straddles multiple styles and genres simultaneously. This results in complex roadmaps for the actor to navigate moving in and out of varying the styles in which they perform. Multiple conventions affect an actor's understanding of the text and influences their ability to execute the task. Awareness of genre and style, of lack thereof, affect an actor's process; ultimately, one cannot play a sport if he or she does not know the rules of the game.

This chapter will discuss the background of the playwright, Lauren Gunderson, her style, the influences for writing Exit, Pursued by a Bear ${ }^{3}$, and the play's role as social commentary on the female body as an object within romantic relationships.

\section{Chapter Two: Director}

One of the first things the actor encounters is the director's point of view with the text. The director is the first encounter with the text. Before rehearsal commences he or she is the instrument to decode the roadmap of the playwright; the chief investigator per se. Actors rely on the director, sometimes a detrimental amount, for clarity in the execution of plot. The director serves as the internal balance and checking module for the playwright's vision and actor's

\footnotetext{
2 "Any piece of information or activity written into the script or demanded by the director comprising the imaginary framework within which an [the] action [of the play] is performed" (Bruder, Melissa, et al. 88).

${ }^{3}$ Exit, Pursued by a Bear will also appear as Exit in this document.
} 
interpretation. Moreover, they are the liaison between the moving parts of technical demands, the visual storytelling aids (be it lighting, costume design, or scenic construction) which accompany the script.

A well-received production is attributed to talented performers, while an unsuccessful one is ill marked as poor directing. The director's role is paramount to the success of a performance, clarity of storytelling, and maintaining the truth of the playwright. A director's understanding, interpretation, and communication of the text can greatly improve, or hinder an actor's character development and consummation.

This chapter contains excerpts of an interview with director Irene Alby. It will present the education and training that influenced her directing style, as well as the conventions that manifested from her expertise in the experimental world of performance. Additionally, it uncovers casting's influence on the story; and how race inadvertently becomes a character that affects the audience's interaction with the text.

\section{Chapter Three: Text Analysis}

Text analysis provides a greater understanding of the playwright's written language outside of performance. The actor succumbs to various demands when inventing a role, the very basic questions, who am I? what do I want?, become daunting inquiries when specifying a character. Be it subconscious, or consciously, analysis of the text provides solutions to these queries. However, an actor is not allotted the time to investigate the minutia of each manuscript. Text analysis, while completed on some level by the actor, is a scholarly attempt to decipher the playwright's use of symbolism, metaphors, and genre. These tools form a solitary literary language. The performance is an interpretation, it is accessed only through the lenses of the director, design, and actors. This chapter will explore the written language of the playwright, 
what Gunderson communicates from the page, and extends to the reader. This intimate exchange is the most authentic voice of the story, because it is not muddled by the point of view of others during the creation process. Investigation in this unit will be placed on themes, the influences of Brecht, Aristotle, as well as trademark American social and political themes.

\section{Chapter Four: Actor's Process}

An actor's chief nemesis is the battle of self. In all humans the conscious and subconscious minds function as the catalogs for a person's fears, anxieties, successes, failures, pain, accolades, victories; the list is infinite. Yet, the athlete that wins separates themselves from the analytic, judgmental traits of the intellect, and respond to sport physically. The skilled competitor will slow the game down to play at his or her preferred speed, maintaining ultimate control, and the opponent becomes simply a bystander. He or she does not entertain the urges of the brain, but instead engages carnal impulses. The exercise an actor must undergo to reach the same physical involvement is tedious and difficult to measure. A runner can test improvement in speed, or a quarterback measurement of throws, however, this same analysis is fleeting for the actor. Doing so creates a debilitating environment that empowers the mental analysis he or she seeks to disarm.

I recognize my shortcomings as an actor is to disengage the opinion of others and myself while in process, but most importantly on stage. Unlike other sports, the game of performance cannot be slowed midstream, but the same principles remain-reach a place of relaxation before entering the playing space. This can be achieved through research, the rehearsal process, and applying various methodologies on the technique of acting. This chapter will showcase the physical and psychological investigations explored to create NAN, the principle character in Exit, Pursued by a Bear. It addresses personal blockage surrounding the text, as well as the 
shortcomings and pitfalls in the research itself. Emphasis is also placed on the interference of racial identity in a text devoid of people of color. It also includes selections of personal journaling which uncover the struggle to disengage the mind, navigating obstacles of insecurity and confidence, and tackling foreign genres and styles.

\section{Chapter Five: Performance \& Reflection}

This chapter documents the pre-ritual process before rehearsal and performance. It details the techniques and methods to distress the body vocally, physical, and mentally. It contains journal entries, and critical evaluation of the production, as well as creative support team. It is a personal teaching tool to address areas of strength and weakness as an actor, ensemble, and dramatic department in collegiate education.

\section{Let's Begin}

What follows is subjective. It is not the gospel. It is a personal account and attempt to articulate techniques that serve me well as an actor $^{4}$, and other times fall flat. It is not fool proof. As I write new revelations are sparking, ideas generating, and contradictory thoughts emanating from one to the next. In the amount of time allotted, and for the sake of this document, I cannot chronicle every moment nor account each step taken to create this role. This document moves through chapters that form episodic building blocks that led up to and beyond the performance of NAN. Additionally, it serves as a record of my development as an actor and scholar over the past three years at West Virginia University's School of Theatre \& Dance. What is most striking is the realization that a process is never complete, but what an actor must solely do is know how to begin. Begin his or her research, world building, personalization, and beginning night after night, stepping on the stage, beginning over, and over again.

\footnotetext{
${ }^{4}$ As an actor I perform under the name, Emana Rachelle. It will appear throughout this document and is interchangeable with my legal name, Imani R. Berry.
} 


\section{Playwright}

In 2017, American Theatre magazine listed Lauren Gunderson as the most produced playwright of the year. Its annual survey of Theatre Communications Group (TCG) member theatres reviewed performance data from nearly two thousand productions. In the 2016-2017 year she hit their list at number two, falling behind August Wilson. Critics find her work refreshing in a male dominated craft because she uses humor to tackle the weighty topic of feminism (Tran). Gunderson isolates her work into three areas,

...plays about history with a kind of feminist understanding or reinvestigation of history and science; wilder, comedic modern plays, sometimes leaning into farce, often with a thread of Shakespeare in them; and the outliers...(Weinhert-Kendt)

Regardless of style, it is refreshing to encounter text that accounts for the experiences of the female perspective without implicit male bias. In her craftsmanship of NAN, we see a woman that is struggling to embody her own worth. What makes NAN relatable are her authentic traits and background that coincide with the author. Gunderson and NAN both have Georgia roots, and NAN gains her strength through her fascination with Jimmy Carter, Georgia's small-time farmer that rose to political fame in 1971 (PBS, "Jimmy Carter" 1). Gunderson has a direct connection with him too; her father previously worked at the Carter museum in Atlanta (Exit Research). Carter is the play's Deus Ex Machina, and NAN's fondness of Jane Austen is perhaps another special nod since Gunderson has highlighted the author in other works. These similarities are not by accident, specifically her fondness of her southern roots, "That's a lot of where Bear comes from - this giddy delight, as well as harsh criticism, as well as a big ol' yee-haw to my people" (Bartelski 27). Even non-southerners or people outside of the state Georgia will find something relatable about the play. 
I love my home-state of Georgia, (and its mountains where I spent many a summer as a child) are rough, worn, shady, lush and vibrant... and yes, there's a bear (Exit Research). While Gunderson uses personal setting as a leaping point into drawing the world of the play, it's her sketch of NAN, the play's protagonist that is the show's driver and delight. The environment is rich, and NAN is just as charismatic as her complex situation. She is the southern belle that has lost her way, and she fights back with all the beautiful ammo she can find.

This is a play I've always wanted to write - a violent play that glitters. A play that calls out the insipid denigration of women in America by laughing at idiots... before leaving them for dead. (Exit Research)

And glitters it does - the manipulation of time is difficult to follow, compounded by the characters moving in and out of present and past while playing one another in a myriad of flashbacks make it a challenge to recreate. Still, there is something enthralling about the text. But this spectacle is heightened by the intensity of its characters. For example, when SWEETHEART, while playing NAN during a reenactment, explains to SIMON how she'd get revenge against her abusive husband,

SWEETHEART. I would tie my husband to a chair and make him understand that what he thinks is right is not right. And I'd do it... with flair. (Gunderson 37) 


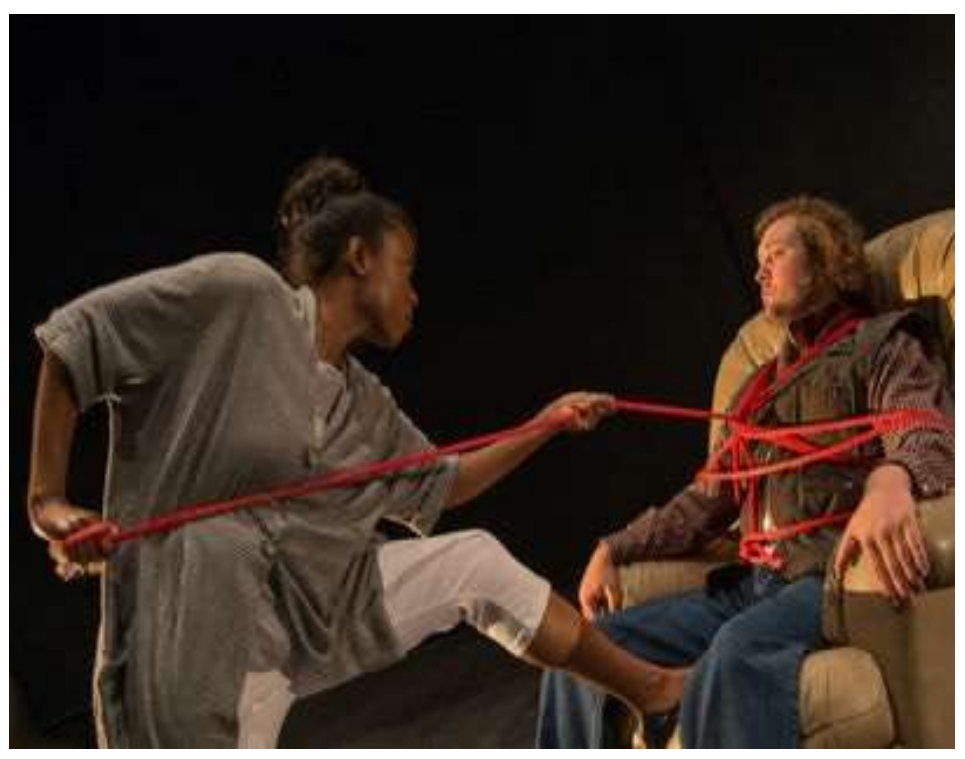

Fig. 1. A publicity photo that illustrates NAN tying KYLE to his recliner (Williamson).

But more than the character's over the top plans, theatre houses must most be drawn to the eclectic energy of Gunderson's work. She is a playwright that manages to throw everything in a production including the kitchen sink. She presents something on the page that leaves you talking about it later, regardless of what part of the country you call home. Gunderson's own admission about her eclectic work, is that some of her plays aren't easily classified.

I don't know if this is my voice or just a crutch. I love plays that have some sort of explosive, transcendent something about the end. Part of it is my frustration that plays have to end at all, because life doesn't; even when someone dies, there's continuance. So there's something false about the ending of a play anyway, which makes me want to run off a cliff with it, if I can. (Weinhert-Kendt)

Exit is an example of this, it straddles the line between spectacle and educational — to teach and to please; both traits of Greek theatre. Gunderson's plays possess the attributes Sarah Ruhl calls the core of all modern American theatre, morality, and mystery (Pollack-Pelzner). Yet regardless of genre, Gunderson's work seems most impactful because she has accepted the charge to create 
theatre that has a deeper meaning, be it presented with farce, her greater mission is to affect change. She says, "I think that's when theater is really doing its job - when you leave in a different place than you showed up (Pollack-Pelzner)."

It is Gunderson's personal charge that is the catalyst for the buzz in her plays. Exit, written as the first entry in Gunderson's, "Will to Power Plays, a series of 3 comedies based on 3 Shakespeare plays" (Exit Research) enlivens the classics such as Exit's namesake reference to the famous stage direction in William Shakespeare's The Winter's Tale, “(Exit, pursued by a bear.)" (Exit Research). The Winter's Tale, a quasi-tragedy, quasi-romance, has all the fantasy and magic of literature, but Gunderson' literal translation of the bears pushes it into a needed space in the contemporary world that isn't stale. She describes it as,

... part I Love Lucy, part Jacobean revenge tragedy, part feminist manifesto, part

beautiful ballet, part nature special, and part 80's power ballad (Bartelski).

While some of the play's themes are difficult to decode, or weave cohesively as the actor, Exit forces its audience to grapple with the disturbances and reality of domestic relationships. With such a heavy message, one can only hope that its audience will leave with a different perspective. However, one guarantee remains. these changes won't happen to Gunderson's audience without a little flavor first.

\section{Director}

Lauren Gunderson's theatrical conventions are dense; they marry comedy, drama, and spectacle in compressed time progressions. Maneuvering through text that holds perplexing qualities is a daunting task, and equally overwhelming as an actor. The director becomes the instrument to decipher the coded language and tie the moving parts of the visual and verbal storytelling into a cohesive thread. In this production, director Irene Alby, an MFA graduate of 
the Acting program at Columbia University, took on the responsibilities of weaving the themes of domestic violence and women's empowerment into a cohesive production, but not without highlighting the play's social and political implications. On December 8, 2017, Alby and I met on break from rehearsal of A Christmas Carol produced by West Virginia Public Theatre (WVPT). She served as the show's director, and I was cast as a principle character. We discussed her development as a director, and her own meanderings on the project. Prior to joining the faculty of West Virginia University, she served as Senior Lecturer at the University of Toledo in the Department of Theatre and Film.

Alby began her undergraduate education at Concordia University in Montreal, Québec. Prior to her graduate education, she trained in mime for three years at the Ecole de Mime Omnibus. She also had the chance to work with Award Winning Canadian Director Stacey Christodoulou. Christodoulou's Company, “The Other Theatre/L'Autre Théâtre, was a bilingual English and French company whose emphasis lay in devised work, deconstructions of classics and avant-garde plays, such as Peter Handke's "Kaspar". Alby recalls the production deconstructing a deconstructed text and adding their own visual storytelling aids such as. film, video, puppetry, and their bodies. Christodoulou's techniques were further coupled by her training with people from the Berliner Ensemble. Politics were always present in the work. As Alby continued working with "The Other Theatre", she began training in "Dojo" under renowned Quebecois actress Pol Pelletier, whose work was influenced by the famed experimental Polish theatre director Jerzy Grotowski, and her study with Baghwan Shree Ragneesh. Every day, the company practiced Dynamic Meditation from 9:00 a.m. to 10 a.m. with the goal of becoming an open channel (Alby). What follows are edited segments from our in-person, as well as digital interview. 


\section{How did you transition into directing?}

I fell into directing, I never thought I would be a director, but it was interesting because I was definitely starting to feel the strain of acting - I love acting but I don't like the business of acting because I don't like having to kowtow. As an actor you are the lowest. It's hard to be a good director, a lot of directors are not very good, if you're a good director you can really do something. It happened to me on several occasions that I was a better director, than the director, and that can be very stifling as an actor, because if the director is pushing you in a direction you know is not right for the character-I mean actors that are successful, are actors who can totally live, they just do their own thingthey don't care about the production as a whole.

I sometimes found, even in New York, that there were directors who didn't understand a play, but they were pushing — but it wasn't always good for the play, or good for the production. I found that once I started directing it was just a natural fit so we started a company in Toledo with other faculty who were professionals from the area, and we started doing our own work.

Alby describes her education at Columbia as the perfect training ground for her experimental director's vision. She trained in the method of physical actions in which her professors taught her to go line by line in the play, a similar trait found in the European Stanislavski way of working. Interestingly, I struggled to find the three dimensionalities in NAN's emotional breakdown such as the one in Scene Three. Alby's approach employed physical nuances that weren't apparent to me.

SIMON. Dammit, NAN.

NAN. Don't yell at me. Don't yell at me. I can't—oh god-oh god! 
SIMON. Shit.

SWEETHEART. Whatwhat?

SimON. She's breaking down.

KYLE. (KYLE knows that he's got an in.) I love you, baby.

SimON. He always gets her worked up and -

KYLE. Honey come on back to me.

SimON. And she gets turned and -

(To NAN.)

No ma'm, do NOT touch that tape.

NAN. I- I need -

KYLE. You need me baby, I know it.

SIMON. (To SWEETHEART.) She needs dessert.

(SWEETHEART runs to the freezer.)

....SIMON. And I'm not doing this bear thing on my own.

NAN. Oh god I brought bears into this. This is horrible! (Gunderson 32-33)

You are a very physical director. Would you say the text hindered, or helped that?

I think it helped, the text really requires it. It's how I was trained, in that European way. My teachers would get us up on our feet and direct every movement, every word. We created a visual language that was as strong as the spoken language. The director I used to work with in Montreal, Stacey, her goal was; a play should have awesome effect, [video], but if everything falls apart we should be able to go outside and do the whole show. And it should still be compelling, and the audience should still be blown away by it even if everything else is gone-no lights, no costumes, no set, everything's gone, but 
with our bodies and space, and use of language, we should still be able to create something very dynamic and powerful.

To accomplish this, Alby asked for exaggerated physical action that captured the manipulation of NAN which manifested into an adult temper tantrum. Throughout the rehearsal and performance process I felt these moments lacked authenticity, Alby describes this philosophy as, Characters are manipulative - the big mistake actors make a lot of the time is trying to be nice pretty and good on stage, but a lot of the time the characters are not nice people, they are manipulative, even in good plays. What I discovered even if you're playing an ingénue, it's a lot more interesting to find the hidden inside of the character. What's that character's secret? That's what Ann Bogart would always say; if the character has a secret, it's much more interesting, rather than just being the innocent girl, which I think is such a sad stereotype in our society that you see in Hollywood all the time. I am so disappointed by female actresses; it's not their fault, the ones in Hollywood, I just feel like they are pushed to play stereotypical roles.

There is a lot of stereotypical stuff and I think a lot of times directors want thatbut girls who are 16,17, 18; they are not innocent and sweet. They are sometimes spoiled, and sassy, and strong, and manipulative. I find that much more interesting and more believable on stage. (Alby)

Alby's words throughout the development of NAN identified issues of fear and self-doubt as an actor, flaws apparent in myself, but qualities not explored in my processes of character development in NAN, and my performance career.

Both in tragedy, but in especially in comedy, it's about the character flaws. If you're scared to be funny, if you're scared to show the character's hidden secrets and selfishness 
of the character, then you're going to end up with something very superficial, because in reality people are selfish.....Niceness is actually fake, nice is not a real thing, it's a cliché. There's a difference between good and nice. (Alby) A large hiccup in embodying the duality of styles in Exit resulted in the cast's limited practice in experimental systems. Deep into the rehearsal process Alby addressed the play's Brechtian style that the full ensemble, myself included, overlooked. This revelation elevated the work into a more playable and accessible space. Many practitioners "miss the mark on Brecht" (Alby).

\section{What would you say Brecht is trying to do?}

He's trying to awaken audiences - I think it only works if you actually create change, a chemical change in the audience. Pol Pelletier used to say; "A show should chemically change the audience." And that's what catharsis is, real catharsis. Real catharsis - put [s] you in a different place. And that's what I thought was so brilliant about Exit, that's what I loved about the play. We had this funny, funny, funny, and then suddenly boom... and the catharsis is so deep, ...the universal truth of absolute generosity. generosity, humility, basically the basis of every religion—-the basis of every faith—every single spiritual book talks about the essence of humanity, of ultimate compassion, then we can have a really huge effect on the audience.

And interestingly I had people come to me and say how they were sucked into the play, because it was funny they got closer to it, so when that moment happens, the final confession between NAN and KYLE, they were completely overwhelmed emotionally because they hadn't expected [it to come]. And because they have been trusting the fact that it was funny, they were totally taken on that journey, and then it just destroyed them. And that to me is catharsis. That's what I love about theatre, it's not about being safe. 
Alby describes herself as an experimental director, one that enjoys texts that can be confusing on the page are a joy for her to dig into. "I like to take a play that's a bit of a puzzle, figure it out just like -actors have subtext, or secrets, great plays also have subtext or secrets (Alby)."

\section{What do you think the play is really about?}

It's the PowerPoint, the video component is a character in this play. And that's why it was so important [to keep]. I knew we couldn't cut those stage directions out.

\section{What challenges did you have find with the text?}

Well, this whole visual language, I was trying to figure it out: this language of the stage directions, and why they were there, and how they made sense and how they add it to it, that was the mystery I had to solve. If you look at them they look random, it doesn't look complete. It seems to be done on a whim - I had to it figure out, what was hidden in that language. And it was there, it was in the monologues, it wasn't just the stage directions, it was also the emoji's in the monologue - there were so many of them, so many meanings, that had other meanings that were so relevant. The catch phrases of the day, the sort of Twitter world that I don't use, and all those emojis that are not a part of my vocabulary, so I had to discover them. And I think when we did it became complete.

\section{Tell me about your decision to expand the amount of projections. Pros? Cons and}

\section{etc.?}

My goals in expanding the projections was to complete the story of the play. I've worked a lot with slides, projections and video in the past, and feel that they add a different vocabulary that is relevant to audiences today. This script called for it in the stage directions, which became a character in their own right. However, as written, they felt incomplete. The more I read the play, the more I understood that there was more to that 
character, concealed within the imagery of the play itself, and I wanted to bring it out through the projection. I think this was even more important based on the fact that we staged it in the era of Trump.

\section{If there was one thing you could change about the final production, what would it} be?

If I could have changed it, or added to it in any way, I would have added even more projections, or better yet, used video to make this "character" even more complete and complex.

\section{Casting}

As a black woman I am aware of the story being told when there's an absence of people of color presented onstage. While persons from groups of the majority may not recognize the influence race representation, misrepresentation, or lack of representation has in art disciplines, it is an inherent aspect of my work as a storyteller. Exit does not discuss race, the absence of it perhaps implies the story is adaptable to all communities, but what speaks louder is its absence. The exclusion of an ethnic minority group as inclusive to the issue of domestic violence shouldn't be glazed over; this omission will be discussed further in Chapter Four. However, the play presents themes on gender politics, feminism, and marital roles in a patriarchal society. It was important to understand how race affected the story for the director, as well as casting.

\section{How would you define colorblind casting?}

To me it means casting based strictly on the ability of the actor to play the character believably, and to go to the heart, the deeper meaning of who the character is. To be able to find the catharsis - humanity, to connect with the other actor in a way that creates chemistry. 


\section{Do you think the difference in myself and Ian's race changed, changes the story?}

Yes. You know it is interesting I didn't plan for it, but since it happened I thought we should use it, that we should let that be there as a part of what is happening, because again it is such a political play, it is so relevant to this time. It wasn't like I said, I need to cast it this way, but you were definitely one of the people who I thought could be really good for the play. When I saw you audition and I was able to put the cast together.

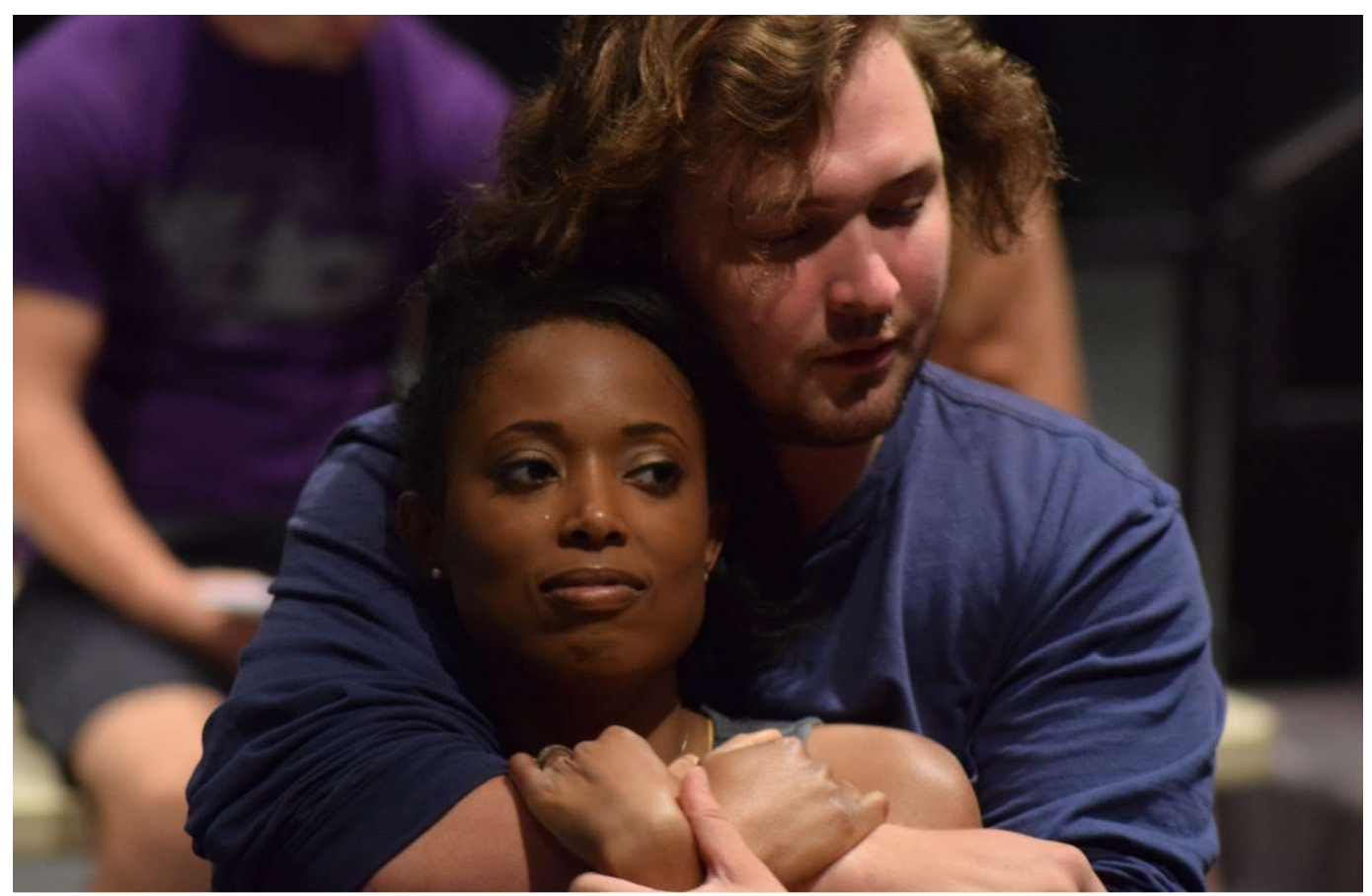

Fig. 2. Rehearsal photo; actors Emana Rachelle and Ian Callahan after KYLE has seduced NAN into revisiting their past in Scene Four (Gay).

\section{Does NAN, portrayed by black woman, symbolize the political and social}

\section{discrimination that is promoted in our society?}

To some degree, the fact that the election happened made me so upset, because this play was meant to be a Hillary win, but at the same time it added another layer of meaning to it. All those "nasty woman" [projections], that was a very specific political reference, "Cheeto induced heart disease," that's what I thought initially, that you should make it 
really political. In the end we found the right balance of being political without being in your face. It became significant and resonated even more, but when I tried to force an issue [the idea of the white actor playing SIMON to be Puerto Rican] I moved away from the universal elements of the play. It was right to back off and just go for the universal, which is always the best. Yes, it [Exit] is political, but never at the expense of what is universal about it. Universal is what will make the play exist in 2000 years; the humanity in it, and the fact that we can all relate to that humanity's deeper truths. That's when we go to that transcendent moment because that's something every human being knows. We all know the hell that exists inside of us, and we all know the heaven that exists inside of us, or at least the potential. Every play is about that struggle between the heart, mind, and soul. You should never lose track of the deeper meaning, I think it's the responsibility of everybody, but I do see the director as the ultimate person who will either make that happen or not.

\section{What do you believe are your three most important responsibilities as a director?}

I believe the director's job is to respect the text and tell the story of the text, but to also try to bring it to the audience in the most immediate, contemporary way. My goal is to draw in audiences of all ages and backgrounds, and I think a lot of theatre has become dated and boring for people who don't feel it is relevant to them.

\section{What did you want the audience to take away from the play?}

My questions are always. how do I make this clear to the audience while drawing out the deeper meanings within the text? How do I solve the problems of the text in a way that makes sense, is believable, and is it transformative for audiences as well as performers? This is my teaching and directing philosophy. 
How do I handle different points of view? I try to make them understand why I am doing what I am doing in order to make them my allies in the process. Once actors understand, they often go even further and bring in great ideas I had not even thought of that go with my initial idea.

\section{What did you learn from this experience?}

Working with more experienced actors is wonderful, because they are talented, experienced, do a lot of work and bring in a lot of ideas. They also bring in more fears (about how they are going to look) and that was the thing that I discovered in working on this play. How to help actors overcome their fears or preconceived notions to embrace something different, or unknown, or unusual, or experimental. I hope that the audience response made them realize that it worked!

\section{The director's vision in - The story}

Alby has a unique directing style, one that throws you in the trenches as you stumble into the ticks of your character. It's a different way of working; it pushes you beyond what is comprehensible and elevates a language beyond the page. She is constantly finding ways to excavate more meaning and enhance the physical storytelling from the text. For example, before the first scene reaches its end, there is a flashback from one year ago. It is the first night KYLE has brought home a slain deer. The stage directions include a tussle between SWEETHEART and NAN, however Alby wanted to capture the machismo, sexual element of KYLE and added SWEETHEART's groping of NAN. This helped provide more specifics about the nature of KYLE and NAN's relationship, and the sexual power struggle between the couple. Additionally, it was directed for the fight to begin near the flashback's onset, instead of near the end of the scene following the stage directions below. 


\section{NAN. NONO GOD I HATE IT NO.}

(SWEETHEART has grabbed NAN, drags her to the deer-

forces her hand all over the poor dead animal.

NAN revolts but "he's stronger,

She convulses with horror and gross-out at this-)

SWEETHEART. NAN. Stopisstopitohmygodohmy-

It'sjustafuckingdeerNAN-hshuthhellup godohmygod... (Gunderson 15-16)

This adjustment added to the dramatic storytelling. The audience isn't sure what will happen, and in that moment, they lean a little more in their seats. If SWEETHEART (KYLE) were to strike NAN with a weapon, it would dilute the alienation affect. Exposing the bad guy early on would prevent the audience from grasping the lesson the show aims to reveal. Additionally, the physical violence at the cause of a weapon is more difficult to suspend the audience's belief, and can descend the show into melodrama. Instead, the appearance of the knife conveys the level of danger NAN lives without affecting the audience's engagement and the plot's evolution.

This scenario, along with the expansion of visual stimuli, and Alby's decision to manipulate time beyond the text, heightened the spectacle Gunderson aims to achieve.

The timeline of the play is very important because it's not linear- sometimes directors take for granted the timeline, even in a nonlinear play, but a timeline in a play is extremely important, the playwright has written something; there's a logic to the illogical. (Alby)

In her analysis of the illogical what manifests is a pregnant woman, NAN, being dragged across the floor, a documentary within a flashback (within a documentary), the sound of ragtime showtunes, projections that go "Pow," and three haunting clickers (for the actors at least), that 
served as advancers for slide cues. These are these entertaining devices, but Alby wants theatre to extend beyond entertainment, "I am always interested in getting at the heart and soul of the audience." Alby sees these entertainment mechanisms as different avenues to spark questions in her audience's psyche.

We can keep it just on a superficial level, we can make it just about now, but the thing that Andrei Serban always said, and he actually quoted Peter Brook, [in] every single line of Shakespeare's text there are seven levels of meaning, and he said I can only find four or five of them-and that's what he always strove for. On one level this [Exit] is political—on another level it's about domestic violence, on another level transcendent, spiritual, an moment of absolute truth where you are faced with the deepest darkest part of yourself, and compassion. It's the idea that there are these cathartic moments in our lifetimes. We live in a time and a place where we take a lot for granted, which is why things are spinning out of control right now. We take things for granted because we have never really had to struggle, I think Europeans don't take things for granted as much, because World War II happened in Europe. Cities were destroyed, and families were destroyed. (Alby)

So perhaps what is truly at the heart of Exit is destruction. The destruction of families in the physical sense, and the theoretical enforcement of patriarchal values on the female body. And while the audience can't articulate that complex convention in the midst of the farce, the funny, or even once they leave the playing space, somehow, they are affected. Just as the performers are affected by the challenge to access the character's fears, victories, and what it stirs not only in themselves, but in the lives of those closest to them. For instance, KYLE, played by Ian Callahan, shared his father's reaction to the play's violence, the tears he shed, and the play influencing him 
to make personal changes. Or the three-hour rehearsal dedicated to myself and Ian reaching an understanding in our deferring points of view in relationship to racial discrimination and police brutality in America. Perhaps these are the chemical changes Alby strives to reach. They are the shift both Alby and Gunderson pursue in their rock-hard perspectives that resist ease.

Nevertheless, their methods are a puzzle the actor must maneuver through. What results from their use of the written and corporal spectacle are those seven levels Alby references in the standpoint of Peter Brook—artistic, political, sexual, racial, social, economic, and patriarchal. We know Gunderson has placed some of these land mines there purposefully, but who better to set them off than Alby. When the smoke clears there's a transformation, some conscious, others unconscious, some lasting, others for a moment. Whatever they are, these chemical changes are rhythmically timed to the sound of fireworks fizzing in the air.

\section{Text Analysis}

Theorist, playwright, and activist Bertolt Brecht is well known for his Epic conventions that deconstructed the widely accepted characteristics of Realism. One trademark of Realism employs the fourth wall as an intentional separation from the conflict presented onstage. Brecht shifted the gaze of the audience to be engaged in the storytelling (Cash). To accomplish this, he removed the fourth wall and addressed the audience directly. Additionally, he implemented the term "spectator," in place of "audience." This altered the role of the onlookers from "one who observes," to "an active participant." The spectator's compliancy became equally vital to effective storytelling. Additionally, the term encouraged a more active role in problem solving the politically charged situations presented onstage.

Text analysis will be used to investigate and address the development of character in Exit, Pursued by a Bear as it informs the actor's performance, as well as what the written text 
communicates to the reader. Before becoming the actor performing or preparing for a role, he or she must first begin as the reader. The artist's first encounter with the text as a reader is equally telling and influential to the performer's execution. Examination will be placed on the reader, and what is communicated to the audience through the performance of the written word. Additionally, the terms spectator and audience will be used interchangeably for sake of clarity, but this exchange should be isolated to this document only. Within the profession there is a marked distinction between the two. This chapter will explore those qualities befitting to Aristotle and Brecht that occur in Exit, Pursued by a Bear, and how these techniques characterize the piece as a drama and Epic simultaneously.

Exit, Pursued by a Bear dances between the worlds of Realism and Epic theatre. At its core are pragmatic stakes; i.e. a husband begging for his wife's forgiveness, and that wife torn between whether to leave, or stay in their physically and mentally abusive relationship. One won't argue that these are real life dilemmas, in 2011 the NY Times reported, "Sexual violence affects women disproportionately, the researchers found. One-third of women said they had been victims of a rape, beating or stalking, or a combination of assaults. (Rabin)

However, Exit does not address these human predicaments in realistic circumstances, or with the tragic standard defined by Aristotle, "Tragedy is not an imitation of persons, but of actions and of life" (Heath 11). Instead of reenacting expected acts of revenge, it exaggerates them through the magnifying glass of comedy and holds it up to the spectator. The audience didacts his or her own opinion instead of being force-fed how to feel. This quality moves the text from a dramatic theatre structure to an Epic one. This exchange occurs when, 
The spectator was no longer in any way allowed to submit to an experience uncritically (and without practical consequences) by means of simple empathy with the characters in the play. The production took the subject matter and the incidents shown and put them through a process of alienation: the alienation that is necessary to all understanding. When something seems 'the most obvious thing in the world' it means that any attempt to understand the world has been given up. (Willett 71)

This "alienation" forces the audience to be active participants, always questioning the truth, and actively problem solving throughout. The audience is dropped into the middle of a chaotic, illplanned kidnapping, the spectator is given little, intelligible background about what led to this moment, who these characters are, and in turn the spectator grapples with who are the good and bad guys at the play's onset. For example, Gunderson describes NAN CARTER, the play's lead protagonist as, "27, female, pretty and quick, like a deer. She wears something comfortable for a hot day" (Gunderson 6). Assigning NAN the zoomorphism quality of a deer designates the impression she is weak, easily excitable, and tender. This description consents the reader to recognize NAN as an unassuming victim. From this first meeting with NAN one may gather she is our underdog, who we want to win; and immediately, in that one phrase, we do; we want NAN to triumph. This feeling is even more prevalent when NAN reveals she has been the target in her domestically abusive relationship, this is her first-time asserting power.

NAN. But I will be very clear with y'babe. that was the very last last time you're ever, ever, gonna hit this girl again. (Gunderson 27)

And silently, in our seats, the spectator shouts for her, stand up for yourself, you go girl. This is what a hero looks like, someone disenfranchised taking their power back. However, NAN's retaliation is so radical that the audience finds themselves in a ping pong match. They are unable 
to decode if her outrageous behavior is the effect of a truly battered woman, or if at her core is the play's antagonist. Perhaps this isn't a tender deer, but instead a deer that is manipulative, too sharp-witted, and stubborn for her own good. Our perception of her changes, she becomes something we all identify as less unassuming. It is possible NAN is that deer too paralyzed to move in the road, and in turn damages the hood of our car. The spectator moves from rooting for NAN, to questioning her motives. In NAN's own words the spectator also hears a sadistic perpetrator, she isn't remorseful, but instead relishes in the torture she has outlined.

NAN. And then I cracked your head. Which you probably didn't notice with the whale belly full of Jack you're on. Then I taped you to the chair. Then I finished the iced tea.

\section{(Gunderson 10)}

Is NAN the victim we initially thought, or is she simply a woman who gives as good as she gets? NAN has all the qualities of what we strive to be, she is vocal, a little guy standing up for what is right, refusing to be stepped on, and that's good tragedy, isn't it? Gunderson's dramatic structure is affective not only because of its similarity to the world we know socially, but the character development employs the standard, “...tragedy is an imitation of people better than we are..." (Heath 25). In NAN, we see a victim taking their power back, accomplishing what many wish they could achieve, but we are skeptical of her actions. Initially, the audience does not see the violence against NAN's person, as a result we are unable to judge who is truly the victim. This is complicated by the public's knowledge that women are not the only groups abused in relationships.

But men also reported being victimized in surprising numbers. One in seven men have experienced severe violence at the hands of an intimate partner, the survey found, and 
one in 71 men - between 1 percent and 2 percent - have been raped, many when they were younger than 11. (Rabin)

The nuances of public norms force the text to work with greater coaxing to earn the audience's investment. NAN enacts the self-redemption we all seek through revenge, but these are merely things we think, not things we do. While her acts are heroic, they leave her teetering between hero and villain, consequently NAN is Exit's anti-hero. In NAN we see the heaven and hell of the human psyche. She possesses all that is good, and equally the capacity to be what is not-evil. Consequently, for NAN to be elevated as the tragic heroine, one whom the audience praises, she must confront the flaws that have brought her to this pit of rage. She must explicate her position. Using the Epic theatre's tool of direct address, Gunderson achieves this feat, breaking the fourth wall allowing characters to persuade the spectator on whether their predicament is worth salvation. Before Exit can succeed in this task, it must first address the social and artistic obstacles that careens the play amongst another set of distinct parallels.

\section{The Rub}

Socially, the play's challenge is the bystander effect, a psychological construct which “discourages an individual from intervening [on behalf of another] during an emergency situation (Bystander), specifically within a public atmosphere. It is this same unspoken apathy, or transient responsibility, that allows the spectator to remove him or herself from advocating for the play's victim, NAN. Even more so, the text leaves the onlooker questioning, "Who is the victim?" This uncertainty produces a greater indifference for the character's plight, because the spectator is unable to determine who's in harm's way. This doubt is man's attempt to be good, he doesn't want to knowingly root for the bad guy, and thus results in his cynicism. NAN, Exit's simultaneous protagonist and anti-hero, is fighting for favor from the first scenes on set. While 
we are interested because of the play's dramatic storytelling elements, we become invested because we want to know if our inner speculation is right; does she deserve to be saved, or is her failure self-inflicted? This speculation is manifested by the presence of violence, specifically masked violence. Without a distinct initial perpetrator, the audience is hesitant to trust NAN, the character in power at the play's opening.

Artistically, the play must work against one of Aristotle's characteristics of tragic structure found in his "Primacy of plot," "...the most important devices by which tragedy sways emotion are parts of the plot..." (Heath 12), but this persuasion is hollow. It leaves the audience removed from the events, they are present in the performance of the tragedy, but they themselves are not affected by the text. Brecht describes this as,

The dramatic theatre's spectator says. Yes, I have felt like that too-Just like me-It's only natural -It'll never change-The sufferings of this man appall me, because they are inescapable - That's great art; it all seems the most obvious thing in the world-I weep when they weep, I laugh when they laugh. (Willett 71)

But what does this drama trigger the audience to do? The spectator is encouraged to feel, but not to incite change; they are stuck in the paralysis of the bystander effect, expecting another to heed to the charge of the victim. This typical drama is entertaining, emotional even, but the outcome is bereft. The spectator will continue to come and go, leaving the problems they saw in their house seat for the next patron to take up for a moment, and leave resting for the next ticket holder. However, since Exit incorporates qualities of Epic theatre, specifically direct address, the spectator must decipher whose side to be on, the protagonist versus the antagonist. Exit showcases this in Scene Two during the character's attempt to persuade the onlooker to their side. Like Epic theatre, the play's plot is fractured (Cash). The following scene is broken into 
four individual sections, each character breaking the fourth wall with a monologue and pleading their case directly to the spectator; we will be looking at three of those moments.

TWO.

A)

Ding! Spot on. NAN.)

NAN. I thought you might be trying to figure out who side you're on.

'I'm not a violent person. But it's like when you get a project in your head - like an herb garden or by the new pair scissors- and you just can't focus till it's done? Well I just cannot rest until this is done. "This" means KYLE, and "done" means bear? (Gunderson 17)

SWEETHEART, one of NAN's aides in the kidnapping explains her involvement,

B)

\section{(Ding!}

Spot on: SWEetheART.)

SwEETHEART. Here's my deal, y'all.

'Two months ago I was on my way to audition for Hamlet at the Dahlonega Community Players when I first saw Nan. She was at the Subway just tearing through this foot-long with all that stringy lettuce and crying and mauling those poor SunChips.

'And I thought this is real drama. Investigate. (Gunderson 18)

At this point in the play the spectator is still gathering facts; they are not sure who to believe. KYLE, NAN's allegedly abusive husband, has been gagged and duct-taped to his recliner. He has only spoken short, pressured responses during NAN and SWEETHEART's make shift interrogation. This is the first time the audience hears his point of view. 


\section{C)}

\section{(Ding!}

Spot on: KYLE.

Still strapped to his recliner but more of his old self. Cocky, bossy, and manly.)

KYLE. I think we got off on the wrong foot here. I'm not an asshole. For real. Listen to me, I don't know why she's pitching this fit in front of everybody but....

'OK. I hunt. Ok. She's never had a problem with it before....

'You don't believe me. I can tell you're sittin' there thinkin' she might be right about me. That I just might deserve....

'I'll be straight with y'all I don't know how this is going to end. I really don't.... I'm trying to say that she's lost it—And we are not safe —And I don't deserve this! Who deserves this? (Gunderson 18-19)

In these monologues the characters recognize the audience as onlookers and persuade them to become involved in the storytelling, not simply be affected by it, but an active participant in seeking the facts. In contrast to dramatic storytelling, each character outwardly coaxes the spectator to their truth. In doing so, Exit straddles both dramatic and Epic theatre qualities. Dramatic because the tragedy closes with its principal characters experiencing Aristotle's reversal and recognition.

A reversal is a change to the opposite in the actions being performed....

Recognition, as in fact the term indicates, is a change from ignorance to knowledge, disclosing either a close relationship or enmity, on the part of people marked out for good or bad fortune. Recognition is best when it occurs simultaneously with a reversal, like the one in Oedipus. (Heath 18-19) 
This reversal and recognition that Aristotle describes is seen in the change we experience in both NAN and KYLE. Instead of allowing KYLE to be devoured by the bear she has covertly lured to their home, NAN is his savior, both physically and metaphorically. The interchange that follows is from Scene Five. It shows an angry NAN, one that is erratic, and unconcerned with the vehemence of her bear trap.

KYLE. This's-this is cracked. This is outrageous.

NAN. It is an outrage. And when Anderson Cooper or Ellen DeGeneres asks me "why? Why did you abandon your husband and leave him for the bears?" I will say. "Anderson? I was outraged. And I decided to do something about it.” (Gunderson 50)

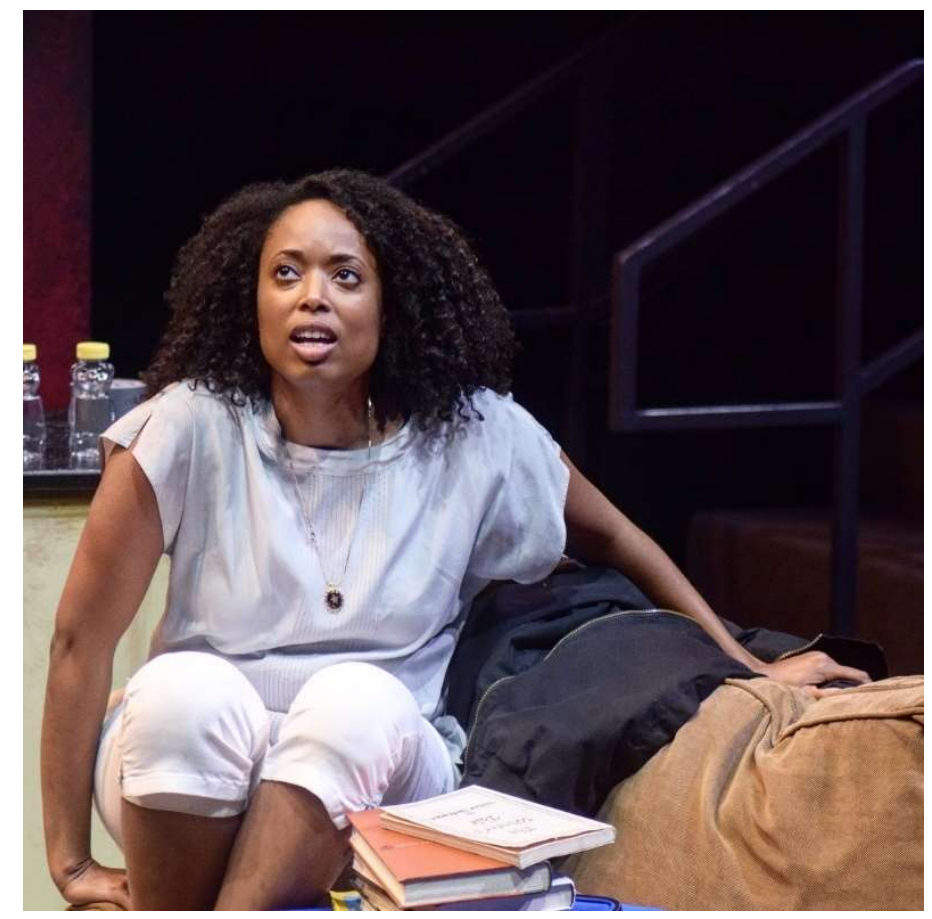

Fig. 3. Rehearsal photo of Nan (Rachelle/Berry) in Scene Five (Gay).

"And I will know my life was lived with purpose." (Gunderson 50)

Later in the scene, as the play reaches its denouement, we see a transformation in NAN and KYLE. He has traded his boisterous, misogynistic temper for a more tender nature, and in his change NAN is able to recognize this character reversal as genuine. 
NAN. And when he forgot it, it was truly born. And like a mean, jealous, and horrible king you started to kill everything you loved. And almost did....

KYLE. (Soft tears, sincere:) You should...maybe...go. But I'm so sorry. Oh my god. (Beat)

NAN. There you are....

KYLE. Oh baby. Baby please. I know I don't deserve it but please stay please, let's start over,

Just you and me and-

(She tapes his mouth)

(A brand new idea. Like she's figuring out a joke.)

NAN. Oh wow. I just got it....

‘And I don't need you. Anymore. (Gunderson 53)

In NAN's final moment with KYLE she reaches her heaven, the heaven the audience has wanted her to be, and the spectator can choose her to be the hero. In that moment they decide the abuse she has experienced is wrong, not because they were told, but because they have witnessed her inner conflict in the public sphere. This communal combat transcends the bystander from a spectator, to a changed willing participant. This transformation in NAN is easier for the audience to accept because they have watched her descend into the seduction of her once destructive relationship, rise more confident and even tempered. There is a marked growth from the emotionally unstable NAN we see in Scene Three.

NAN [to Simon]. Don't yell at me. Don't yell at me. I can't - oh god—oh god! SIMON. Shit.

SWEETHEART. Whatwhat? 
SIMON. She's breaking down.

KYLE. (KYLE knows that he's got an in:) I love you, baby.

SIMON. He always gets her worked up and-

KYLE. Honey come on back to me.

SIMON. And she gets turned around and(To NAN.)

'No ma'm, do NOT touch that tape.

NAN. I-I need- (Gunderson 32-33)

In Scene Five NAN departs her relationship with peace minus the "grand ole" spectacle of violence. Watching the characters plead for their innocence in Scene Two provides a duality in which Epic structure allows the subject matter to become accessible. On one hand the mere inclusion of KYLE's direct address implies they, NAN \& KYLE, are equally at risk for being harmed. This adds to the complicit act all audience members undergo when stepping into a theatre space, all parties agree to accept what is presented as truth. However, the manner in which Gunderson breaks the fourth wall elevates the stakes. Instead of seeking empathy, the character's pleas transform the space to that of a court room. Each side presents their case and provides evidence to support his or her position. The spectator becomes the investigator, this adds a greater level of investment with the audience serving as the jury. Regardless of which side they believe; their ultimate goal is truth. Perhaps what is most effective is not the characters being viewed as believable actors, but humans on trial. Exit emphasizes the belief that when performing on a stage the character is truly fighting for his or her life. In doing so, it produces the greater audience investment Brecht describes as the A-effect. Gunderson's use of satire, characters that break the fourth wall, gesture, and the personification of stage directions employ 
Brechtian principles to achieve audience persuasion. Gunderson herself describes comedy as a tool to tackle sensitive topics (Exit Research), an Epic trait. Brecht teaches us that in contrast to dramatic theatre, the Epic spectator and production must take the subject matter, and the incident shown, and put them through a process of alienation - the alienation that is necessary to understanding. These elements of Epic theatre do not tell the spectator to feel, but instead encourages them to alienate the solution to the predicament presented (Cash).

\section{Gesture \& Mime}

Gesture and mime are physical devices that create comedy and mark the alienation or A-effect. The aim of this technique... was to make the spectator adopt an attitude of inquiry and criticism in his approach to the incident. The means were artistic. (Willett 136)

These manifestations are the physical action, and the negotiation the actor must make between the written text and corporeal storytelling.

Gesture, mime, and everything acoustic is considered especially praiseworthy if in them more is expressed or made visible than the mere words say. The point is the scenic utterance. From the beginning, Brecht conceives of dramatic speech as spoken speech. It needs the gesture and the partner; it is a literary basis, it contains what the persons say; but the play as performance presents more than that. And here is where the "vital," "unliterary" actor places his accents, here he interprets and is already making decisions. That is also possible in the theatre of illusion. But this is the spot where the reviewer subsequently breaks away. (Hecht 44-45)

Through gesture the actor does not recreate Realism, but instead he or she externally exhibits their emotions (Willett). This exaggeration forces the audience to reconcile with the larger message and intent of character within a social context. 
The emotion in questions must be brought out, must lose all its restrictions so that it can be treated on a big scale. Special elegance, power and grace of gesture bring about the Aeffect (Willett 139).

It is difficult to recreate this task with Realism, and even more difficult to fashion an author's technique of alienation or A-effect without their presence in the rehearsal hall. However, Gunderson employs the personification of its stage directions to accomplish this. Before the characters speak, these directions are the audience's first introduction into the world of the play. They serve as the spectators' first character interaction. The opening scene begins with.

A)

\section{(Ding!}

With bolded stage directions projected somewhereSpot on:

A doe's head. Stuffed.

Like it's caught in a headlight...

Which will tell us why it's stuffed.)

\section{B)}

\section{(Ding!}

Add a spot on:

NAN...

Caught in a headlight...

She looks at the deer...so sad that it's stuffed.

\section{So mad that it's stuffed.}


The anger turns her around to face:)

\section{C)}

\section{(Ding!}

Add a spot on.

KYLE...

\section{Duct-taped to his recliner.}

So sad he's duct-taped to his recliner.

So mad he's duct-taped to his recliner.

Ding!) (Gunderson 9)

These visceral stage directions generate another character.

This is a play based on stage direction, so we're allowed to see them. Along with the PowerPoint and Karaoke lyrics, projections of any bolded stage directions should be used to clarify time (i.e. "six years earlier"), context, or things of general wit or import. (Gunderson 6).

While the instructions do not tell the spectator how to feel, they are active tools that affect the storytelling, as well as alienation tools that develop opinions about other characters in the ensemble. Three victims are presented. The deer, symbolic of NAN as KYLE's prey, NAN herself, the stunned, physical manifestation of the innocent deer, and KYLE, now tied up and unarmed, his restraints communicate foul play against his person, but also his potential to harm. These stage directions are an expression of Gunderson's world in which the spectator must negotiate its own truth and thus evolve into its own artistic expression.

The actor must make it possible for the audience to take its own art, his mastery of technique, lightly too. He puts an incident before the spectator with perfection as he 
thinks it really happened or might have happened. He does not conceal the fact that he has rehearsed it, any more than an acrobat conceals his own training, and he emphasizes that it is his own (actor's) account, view, version of the incident. (Willett 139)

The stage directions gesture ideas about the story just as Brecht calls on the actor to do above. NAN. 'Ok. Yes. No. Let's just do the next scene before he comes.

SWEETHEART. I await your cue. (Gunderson 12)

(SWEETHEART actor-prepares in the corner.)

Later in the scene we see,

NAN. ....We got a dead deer in the truck?

(KYLE nods, mumbles.

NAN and SWEETHEART squeal in excitement!)

Oh my god!

SweETHEART. Oh my god! For the scene!

NAN. For the scene! Perfect!

SWEETHEART. Ohmygod it's perfect! (Gunderson 13)

Just as we see the characters reference their rehearsal, the stage directions do the same. These mechanisms are farcical tools to make a heavy social issue more palatable and are elements of the plays A-effect. Because the stage directions are so vital in negotiating the spectator's belief, they become the play's fifth character. While the deer is symbolic of NAN's innocence, it doesn't stand up and say, look at this. However, the stage directions [both those offered by Gunderson and Alby] are characters of their own. They vigorously navigate the play's truth and ultimately its overall message on domestic violence. 


\section{The Power of Symbolism}

Symbolism is expected in the poetic medium - the language an author crafts of metaphors, and imagery evoke emotion from the reader and orator. A tree symbolizing the fertility of life, a dark road referencing the journey into death, or a blazing fire reflective of passion. These images are reflective forms of the human experience. It is poetry's melodic elements that reckon it to the visceral response we receive in music. In the theatre these symbols may not always be so clear. There are times where we find ourselves mining for symbols that are not even there. However, in addition to all the literary devices previously discussed, Gunderson adds this concept of symbolism in both the deer and Jimmy Carter. The inspiration and exploration of the deer to create NAN's psyche and physical life will be discussed further in the following chapter on Actor's Process, this section will look at the use of Jimmy Carter.

During NAN's direct address to the audience she describes the many things that led to this moment, her being trapped in this relationship, and her zany scheme to get out. What is most telling is the regard she holds for Jimmy Carter.

NAN. I'm one of those women that you look at and think, "Why doesn't she just leave?" Well I didn't leave until now because I'm broke, and I'm stuck, and I'm scared. I am scared.

'I am NAN Carter. And I wish Jimmy Carter was my dad but he's not. 'I am NAN Carter. And I wish someone had told me to wait to settle down, and to not be so sweet, and to move to Atlanta after school, and to seriously consider professional soccer-y'all I was so good — and to not marry the first one...(Gunderson 17)

In the flashback date scene with KYLE in Scene Four we learn NAN's dad is dead, but it is the impact of that death on NAN's psyche that is crippling and influential in her inability to leave. 
Thus, while Jimmy Carter symbolizes the underdog achieving greatness just as President Carter did in the 1976 election against the incumbent President Ford, he is also NAN's symbol of paternal nourishment. The absence of her father has created an appetite to be loved by a male figure. This lack of love has ultimately led to NAN's relationship with KYLE, and the deer paralysis we see in Scene One which symbolizes her inability to abdicate her marriage.

Carter is so many things. He is her desire to move to the big city, Atlanta, a symbol of ultimate success. He is the nice guy finishing first, but just as he symbolizes triumph for the Georgia girl, he is simultaneously the charge and helpless change in a fractured system. The references to Carter's 1979 speech, "Crisis of Confidence," is a direct address to the spectator's personal negligence on the topic of domestic abuse in their own lives, or that of a neighbor. Their inattention to the matter is challenged, just as the dysfunction KYLE and NAN symbolize are on trial.

(While they pack up, and finish the meat fort NAN recites the following...)

(Perhaps actual footage of the Carter's '79 Crisis of Confidence speech projects -NAN and Jimmy speaking at once.)

NAN. "I want to talk to you right now about a fundamental threat to American democracy.

It is a crisis of confidence."

..."We can see this crisis in the growing doubt about the meaning of our own lives and in the loss of a unity of purpose for our Nation."

... 'But we've always believed in something called progress. We've always had a faith that they days of children would be better than our own." 
... "In closing, let me say this. I will do my best, but I will not do it alone. Let your voice be heard."

... "Let us commit ourselves together to a rebirth of the American spirit. Working together with our common faith we cannot fail." (Gunderson 54)

This excerpt symbolizes America's social complacency. Thirty-nine years have passed, and a crisis remains. Just as in 1979 the Carter's speech was a charge for the public to take inventory of their own participation in "unemployment, inflation, and the energy crisis (Weekend Edition). In a 2009 interview author, Kevin Mattson describes Carters efforts as,

He tried to push the energy crisis on to a kind of moral and civic plane, and the speech was used to unify around a sense of civic sacrifice (Weekend Edition).

Carter is the symbol of NAN's lost father, and the symbol of the civic duty the public must employ on the issue of domestic violence-Carter is ultimately NAN's hope for a brighter future. Gunderson employs it for the same charge, but it too symbolizes the lack of progression the collective country has been able to accomplish on the issue. Just like Carter, NAN pleas to KYLE for change,

NAN. Do you understand what's about to happen?

(He shakes his head "no.")

It's called a soliloquy KYLE. It's a little speech you give like no one's watching. You say stuff you wouldn't say, reveal your motives, and really just feel your feelings out loud. Which is what I never saw from you. Which just might save your soul. (Gunderson 51) 
KYLE symbolizes the American public, and NAN is charged to encourage him to change, along with the spectators, who are equally charged to change. Ultimately, Carter is the symbol we hope for and the change that is nonexistent still thirty-nine years later.

Exit, Pursued by a Bear is loaded with poetic devices and examples of theatrical theoryRealism and Epic, and spectacle which stimulate its audience. While the myriad of tools can be disjointed when tackling the piece as actor, i.e. working through multiple styles can be overwhelming, it is the actor's responsibility to decipher these thematic elements and present them in a well translated performance. This section has analyzed the text from a theoretical point of view, what will follow is places these theories into action. At the core of Chapter Four, "Actor's Process," is the ultimate question-how does an actor use the puzzle pieces in practice to create accessible theatre along with three dimensional characters?

\section{Actor's Process}

\section{Finding $N A N$}

The method in which I develop characters has evolved throughout my professional experience and academic training. My approach has always dealt with the sensory exploration of my past and historical research to embody what is given to me in the text. The three years of study at West Virginia University (WVU) has expanded my previous training in the Method as outlined by the Lee Strasburg Institute in association with New York University. This training deals primarily with sense memory and emotional recall. Over the course of my matriculation at WVU, I have expanded my approach to human development as an actor to include principles found in Sanford Meisner's mottos, “Acting is doing," and "acting is living truthfully under imaginary circumstances." NAN was a direct product of a combined exploration of the above- 
mentioned methodologies along with Uta Hagan and Michael Chekhov. Each of these acting methodologies are expansions of and based on the work of Constantine Stanislavsky.

Furthermore, an area of great personal difficulty has been creating a character's physical life. It is much more instinctive to develop a character from the inside out, but doing this method alone creates a hollow element to the character's comfort on stage. This results in stiffness, or the suppression of physical instinct. Specifically, the development of NAN was a direct correlation of my recent study at the British American Drama Academy (BADA) in Oxford UK the summer prior to rehearsals. There I was introduced to the movement principles of Jackie Snow. Her training and book, Movement Training for the Actor, along with the accompanying DVD and workshop intensive (which included a series of in-person exercises) allowed me to explore the physical freedom and construction of NAN throughout rehearsal and performance. The sections to follow will describe the tools and methodologies I used to find the human life and character of NAN both physically and emotionally. This will be accomplished through a series of journal entries during my preparation for the role, reflections on process, acting theories, and meandering on the manifestations of this role.

\section{NAN's Point of View}

\section{Physical Research}

Significant challenges for the actor in this play is humanizing the author's animalistic description of the characters. When encountering NAN I was not aware of the physical demands the director expected to employ. NAN's trait, "quick like a deer," provides an indication of her speed, but how this would manifest is unclear. This character reference can easily be translated as whit, or vulnerability. The documentary, "The Private Life of Deer," provided a better understanding of the animal's physical qualities that were transferable to the stage. For instance, 
the term deer caught in a headlight is a result of information overload. A deer's vision is best at night, however, the light from a car's headlight shines too much information into the animal's eyes which affects the deer's ability to move. Because of the deer's keen visual sense, too much of this stimulus results in paralysis. Thus, the well-known crippling trait because the animal is afraid is incorrect, because it is instead experiencing a sensory overload (PBS, "Private Life of Deer"). To translate this into NAN, I allowed the paralysis to ignite at varied moments when KYLE spoke, depending on his need, i.e. him begging for forgiveness, or during a verbal attack. This disabled state is also seen when SWEETHEART enters the stage as KYLE.

NAN. Let's review.

First thing honey. You've been recast.

(SWEETHEART; a hot girl playing KYLE, enters.)

NAN (continued). Second. This is SwEETHEART, whose stage name is Peaches, who's playing you.

SWEETHEART. Hi.

NAN. Third. This. Is what. Just happened.

(What Just Happened...

"NAN cues SWEETHEART who bursts in "drunk.")

SWEETHEART. You dumb stupid—-left the godamn rake on the-

Goddamit, the longest, dumbest day, and the traffic — and the truck, and the damn deer, and can't even get in my own damn house without a damn booby trap-

NAN. I'm sorry

SWEETHEART. Fuck sorry.

(SWEETHEART smacks NAN hard on the face.) 
SWEETHEART. Why don't you get me a beer.

(No beer tonight, baby. NAN picks up a frying pan-then turns to KYLE.) (Gunderson 10) At the start of this scene, during her exposition to KYLE, NAN possess a relaxation throughout her body and a sense of control. There is a moment that NAN is alone on the stage before SWEETHEART's entrance. During that time, NAN's frazzled energy was funneled into preparing KYLE's dinner for the evening. This choice was made to specify NAN's routine that ensures KYLE is comfortable when arriving home after work. During this moment, the deer qualities are seen in NAN's unsteady nature, but there is some relaxation in the body. This changes at the sound of SWEETHEART entering the space as KYLE with immediate tension throughout the body. This results in a moment of being frozen, then a shift to cowering, and the frantic energy often seen in deer when they are fleeing danger.

As mentioned previously (see Chapter Three), the flashback in scene one was altered to include SWEETHEART approaching NAN with a knife. Traditionally the deer flees at the sense of harm, and the knife symbolizes the light paralysis seen in the creature. NAN has dealt with verbal abuse before, but this is the first time she has known her husband to kill.

SwEETHEART. Hey, look at this shit!

NAN. Jesus. What did you-KYLE!

SWEETHEART. I shot it, baby. Da-dead da deer-ass dead.

NAN. WHYWHY? NO! WHY?!

SWEETHEART. Cause it's stupid and thus deserved what it—quit getting pitchy—There's a surplus of 'em and we're gonna eat it.

NAN. I AM NOT, GET IT OUT!

SWEETHEART. That's my meat! 
NAN. You killed it?!

SWEETHEART. Hunting season means huntin' shit.

NAN. You don't hunt!

SwEETHEART. I shot it and it's dead so it's hunted so I hunt. (Gunderson 15)

NAN is cornered by the imaginary fourth wall when SWEETHEART approaches her with the knife pointed toward her face, additionally, this paralysis is also a reflection of the change in stakes. She does not run, or flee, because the new information about her husband's violent demeanor is debilitating. The exploration of paralysis in NAN's physical demeanor added a much-needed contrast to the energetic quality also seen in deer.

In contrast to the deer's moments of stagnation, the animal is also well known for being easily startled. To capture this element of distress NAN flings her limbs without prompting to maintain a position of authority for fear she'd lose the charade she's playing with KYLE.

(He squeals and squeals, SWEETHEART claps and claps. NAN cues SWEETHEART who rips off his mouth tape.)

NAN. (Continued:) What.

(He gasps)

KYLE. Truck.

NAN. What.

KYLE. Wrecked

NAN. WHAT.

KYLE . Wrecked the truck.

NAN. Oh you did not-

KYLE. Hit a tree. Hit a deer then a tree, mainly a tree. 
NAN. You killed a deer.

KYLE. It's in the back. Truck's cracked. Barely made it home 'fore the thing gave out.... NAN. SHUT THE TRUNK KYLE.

(NAN cues SWEETHEART to re-tape his mouth.)

KYLE. Waitwaitwait-

NAN. I swear. The one night I do something for myself_-THAT's the night you...? I am

NOT WALKIN' after all this, goddammit—after EVERYTHING I'VE DONE FOR YOU. (Gunderson 11-12)

In response to the news of the crashed car, NAN paces backwards and forwards. She shakes her hands lose in effort to get a grip on herself and to processes the plot twist presented by KYLE. The corporeal panic in NAN was captured through short, shallow breaths. Additionally, there was an increase in heartbeat while trying to process the information. While this was an instinctive response, the specificity of the reaction was enhanced by research conducted by watching the HBO documentary, Private Violence.

Private Violence follows the stories of women that are victims of domestic violence. The women interviewed and studied are in heterosexual relationships where the male is the predator. The first woman, who is not named, is visibly several months pregnant; she is living at a woman's shelter in North Carolina where she is fleeing from her abuser. She provided further physical study of the manifestation of panic. In the documentary she is working with counselors in the shelter to arrest her abuser who is in violation of a restraining order by contacting her via phone and attempts to meet her in person. She aids the counselors in leading him to a police entrapment. It was interesting see victim's behavior, her body's resistance to the plan, and her mourning when the plot is successfully carried out. Specifically, she bends her wrist, wipes her 
brow, and cries uncontrollably. This wiping of the brow became a physical trait for NAN. It appeared at unexpected moments in the text, but was always present when she learns of the car being totaled.

Furthermore, NAN presented an ill-ease, and skittish movements when afraid. The investigation of, "deer jump in the wild to avoid the predator," (PBS, "Private Life of Deer") was showcased through erratic gestures of the head jerking from right to left, and the physical impulse to dart across the stage at unexpected sounds. For instance, when SIMON calls in Scene One NAN runs upstage scurrying to the kitchen to retrieve the phone.

(Her cell rings, she answers.)

NAN. (Continued.) Yeah.

No SIMON, it means come over now.

Cause I'm doing it now.

And he went and busted up the truck so we're gonna-

Yes the - yes, would you get gone-And please take the back roads up here cause I know you think you can outsmart Atlanta rush hour but god himself could not get on the freeway right now and I need you like tout freakin suite, SIMON. (small pause)

I don't care what you wear, you're playing yourself. COME ON. (She hangs up.) (Gunderson 13) 


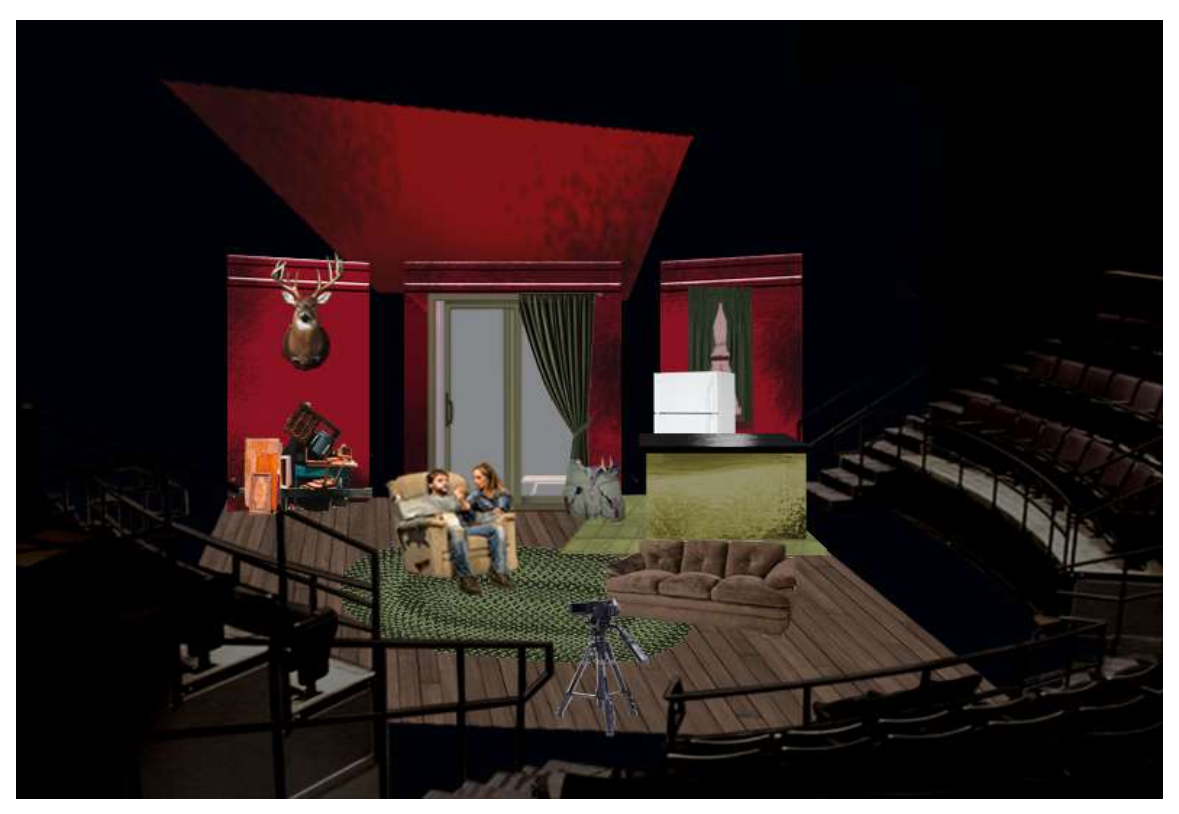

Fig. 4. Scenic design, “Bear Sketch,” August 29, 2017 (Johnson).

When describing this plot foil NAN fidgets in the living room (see Fig. 4). She scratches her head, sits down, stands up, leans back on the couch, and moves back and forth from the center of the couch to its edge. Her frantic nature is also explored through the changes in vocal intensity. She transitions in and out of whining, hurried speech, agitation, outbursts, and shortness of breath. It isn't until the call ends, and NAN has regained control over her emotions that she stands and finds an inner calm. She then showcases the curiosity of the deer not just through her questions, but by feeling safe enough to slowly walk towards KYLE and interrogate him. The section that follows is continued from the previous excerpt.

(....She realizes...)

NAN [continued]. Wait.

(KYLE squeals.)

Did you say you hit a deer?

(KYLE nods, mumbles.)

You said it was in the back? 
(KYLE nods, mumbles.)

Of the truck?

(KYLE nods, mumbles.)

We got a dead deer in the truck?

(KYLE nods, mumbles.

NAN and SWEETHEART squeal in excitement!)

NAN. Oh my god!

“...For the scene! Perfect! (Gunderson 13)

The deer exhibits curiosity, gentleness, and resistance (PBS, "Private Life of Deer"). NAN's physicality embraced all these elements, but the above section exudes this mannerism towards KYLE-her arms drop to her waist, she turns her back to him, and then slowly spins to face him. While this change is a result of the curiosity to seek more information, KYLE's inability to move gives NAN the freedom to be curious without being attacked. She is also figuring out how the new information works to her benefit.

NAN's physical curiosity is seen in the moments where she's drawn to the manipulative KYLE. She is entranced, but cowers from him for fear of being sucked into the false presentation of his intent. This curiosity is the hope that KYLE would turn over a new leaf. In Scene Three NAN asks,

NAN. You're changed?

KYLE. Yes!

SIMON. No he's not. 
KYLE. I will NOT be that kinda man. But you gotta help me, honey. I need your help.

See, it worked. Your whole funky bear plan worked. I get it. And I don't wanna ever be that guy. I hate that guy. I will kill him myself, but you have to help me, penguinpenguin.

SIMON. NAN, this is what he always says.

NAN. Actually I've never heard this before.

SimON. So these are fresh lies.

KYLE. I'm sorry about everything he mighta done.

NAN. And the deer. (Gunderson 31)

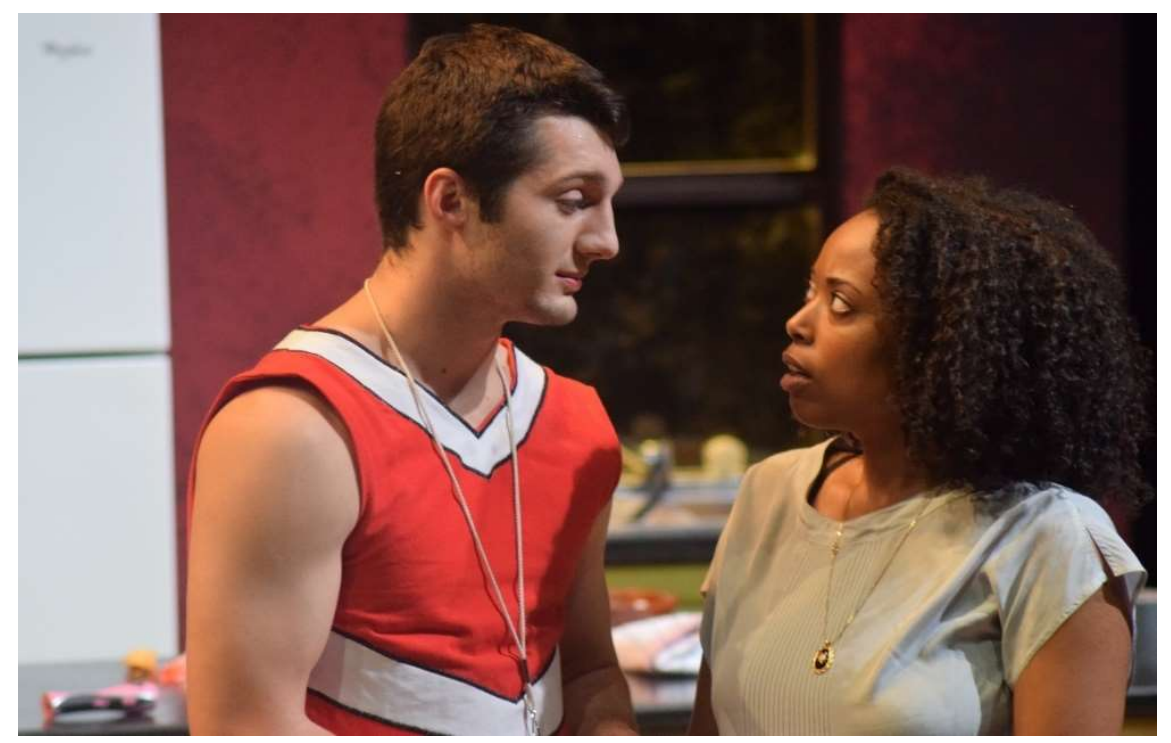

Fig. 5. Rehearsal photo; NAN (Rachelle) and SIMON (Cody Hively) debating how the revenge plan should proceed (Gay).

As the scene progresses, NAN changes from having her back to KYLE to facing him onward. She hopes he is genuine and shows her interest in this change through her questions of intrigue, and by physically opening her heart in his direction. This curiosity is further explored by asking if he is remorseful of the things he's done. The following section is a continuation of the previous dialogue.

KYLE. And all the little creatures he mighta shot in head. 
NAN. And the cat.

SIMON. Jesus wept, how is this working.

KYLE. And he will never touch another animal ever again in his life-no guns-no drinkin—no Fox News-

NAN. Cause that gets him mad- (Gunderson 32)

And just like a curious deer, NAN is drawn to the hunter. She unable to decipher the intentions of his web, and once again finds herself walking towards danger.

NAN's gentle quality is seen in the last seen reaching out to touch KYLE's face and kissing his cheek. The fight in Scene One was choreographed to capture her gentle nature in a reach to cradle KYLE's face, but like the resistance in deer, NAN's caress becomes a violent retaliation to scratch KYLE. NAN's physicality was constantly drawn to KYLE's face, influenced by the curiosity of the deer, moving in and out, but finally leaving him in the final scene by packing her bag. This choice was a result of the Meisner methodology described in A Practical Handbook for the Actor in which acting is always actively doing; therefore, what is NAN doing? Theoretically, NAN is freeing herself from the grips of her abusive marriage. Emotionally, she is finally strong enough to walk away. Physically, NAN is packing her bags. This physical action was a result of constant questioning, exploration, information in the text, along with trial and error. The activity grew in specificity from Gunderson's prompts, but adding books in the home to NAN's routine and other personal items were physical doings to demonstrate NAN's final decision to leave, as well as her relationship to items in the home. The additional manifestation of NAN's internal struggle was investigated during the physical outburst in which NAN grabbed KYLE's clothing from the laundry basket and threw them towards him in her first initiated physical attack against his person. The items were thrown through the air when NAN reaches her 
internal catharsis by shouting, "biological determinism has no effect on me, KYLE" (Gunderson 49). Unable to suppress the mounting frustration of NAN, the physical impulse resulted in wrapping KYLE's shirt around his neck. This rage is the deer's heightened resistance, her final effort to combat the predator. NAN shifts in and out of these states and it isn't until this physical fit that she can articulate being fed up once and for all.

To channel NAN's confusion and weariness, I explored constant shifting and fidgeting in her physicality. To investigate her sporadic energy I assigned her the task of cutting the deer meat, packing items around the home, folding and etc. in an attempt to control her frantic energy. Furthermore, in Scene Three, when KYLE is convincing NAN to stay, the physical response included covering up NAN's ears to shield her from the predator's words. It was important to maintain the attitude that, "these [deer] are wild creatures" (PBS, "Private Life of Deer"). With the direction of Alby, along with the openness and ready impulses that were a byproduct of the physical warm-ups discussed in Chapter Five, NAN moved from her lower trunk which placed her in physical readiness. "They [deer] can jump 8 feet high" (PBS, "Private Life of Deer") this supported NAN's jump to the couch when sharing the news about her pregnancy,

SWEETHEART. ...I am with child!

(NAN looks at the boys.

KYLE is stunned.

SIMON is stunned.)

SIMON. I don't - wait - Is she still talking as you?

KYLE. (Muffled.) You're pregnant?

SIMON. You're pregnant?

KYLE. (Muffled.) By me? 
SIMON. By him?

SWEETHEART. Was my performance not literal enough?

NAN. (To the boys.) It's real, y'all.

Simon. (Confused cheer.) So - wait - Yaay? Or...

NAN. Oh my god, yes, yay! Baby yay! (Gunderson 25)

Her physical convulsions on the couch are a response to KYLE's honeyed words,

KYLE. Nan, honey, baby, come on - for the children - for $m y$ child in your...pouch.

(Gunderson 29).

You see them even in her hysterical crawl towards KYLE, like an animal and heat, before having a complete meltdown in Scene Three (review the quoted scene on pages 15 and 16 of this document).

"A thicket of branches is all a deer needs to hide during the day." (PBS, "Private Life of Deer")

To maintain the essence of the deer's stealthy nature NAN's movements alternated between a slow, calculated circling of KYLE during his initial interrogation in Scene One, and when humiliating KYLE about the future of their unborn child in Scene Three,

NAN. KYLE, I SWEAR, you're killin' the buzz.

I know this all seems extreme. And I know you are not a thoroughly evil person. But as I was sitting on the toilet holding that pinky cross tabulator thing I thought. Oh my god. My husband kill[s] things for fun. He drinks like drunk-ass fish. He is mean to me. That is not the biology, personality, nor context in which to raise a child. (Gunderson 27) 
This attributed to NAN's complex nature as a victim, struggling with her newly found role as the predator, and her trained fear as the symbol of the mounted deer in KYLE's life (see Scene One on pages 38 and 39 of this document.

\section{Speaking in Tongues}

As previously mentioned, Exit is set in the mountains of North Georgia. My own Georgian roots provided a level of comfort when studying the dialect, however, there were regional differences that required intensive study. The setting is described as.

July $4^{\text {th }}$.

A small, musty 1-bedroom house in the North Georgia mountains: the front door opens near a tiny kitchen with sticky floor and a breakfast bar. The living room has a ratty recliner, a folding TV-dinner table, and a TV in a corner. The back wall is mostly a large glass sliding door onto the backyard and tiny patio.

It's all in a style just old enough to be in poor taste—fake wood, something dark inside. Not messy, but impossible to get really clean.

Outside, trees shade their world. (Gunderson 6)

The scenery Gunderson draws is clear; providing a vivid image to access the vocal methodologies taught by Kristen Linklater. Linklater activates the imagination as an avenue to free the voice, "allow individual words to influence your voice, giving a phrase or sentence more life than just what it gets from the overall sense" (342). While Gunderson provides enough detail to access the voice of the character through the imaginary sense, my own Georgian roots are counter intuitive to the world of NAN. Her world is rural and musty, pressed against open air greenery which stimulate drawn out vowels and languid speech. In contrast, my point of reference growing up in the state's capital encompasses bustling sounds of an urban landscape, 
situated against the backdrop of flashing blue lights, sirens, horns honking, and revved engines. What results is hurried speech where vowels are tools to further emphasize declaration, or dramatic effect, and the clarity of consonants are lost. The city maintains the influence of the rural towns with lengthened vowel expression, but it occurs less frequently. While the pace in both dialects differ, both are markedly slower than northern cities such a New York, or Philadelphia, which deem southerners as slow talkers.

NAN's dialect became a marriage of the text and setting requirements, as well as my personal relationship as a fellow Georgia girl. It was important to maintain my vocal authenticity as NAN. Being from the state provided a clearer understanding of the dialect's nuances and a complex negotiation of my upbringing in contrast to the rural locale. Ignoring this connection would result in a caricature of an "idea" of a woman from a rural town. Ultimately, it would result in a disservice to NAN's three-dimensional need to become unstuck and advance to the big city.

NAN. I am NAN Carter. And I wish someone had told me to wait to settle down, and to not be so sweet, and move to Atlanta after school... (Gunderson 17)

Thus, the foundation for NAN's voice was rooted in my own speech as an Atlanta native. The mountainous elements were captured through video study of Jimmy Carter and his wife, Rosalyn Carter. Due to the trait in which politicians achieve a more polished vernacular as they gain popularity, vocal coach Laura Hitt suggested study of the Carters pre-presidential election. ${ }^{5}$ Additionally, the specificity of NAN's sound, and its alteration based on the character with whom she is speaking, was enhanced by my work on the show as assistant vocal coach. These responsibilities included leading and supervising the daily warm-up, sharing source materials for

\footnotetext{
${ }^{5}$ The videos that served as source material to achieve NAN's dialect are listed in the works cited portion of this document and are identified with an asterisk $(*)$.
} 
the dialect, providing vocal feedback on an actor's embodiment of the dialect, as well as vocal safety throughout the show's physical altercations between characters, as well as Alby's demands on the character's physical life.

\section{Character Point of View}

To create a three-dimensional character an actor must grapple with, "what is, their character's point of view." Fortunately, Exit is laden with a myriad of clues to construct how NAN sees the world. Within the play's first few pages of exposition NAN says,

NAN. We've been practicing for you, babe. So you can feel the acute baptism of this moment. See I've been reading - have I been reading some real lady business. The Second Sex, and Jane Austen, and National Geographic Magazine, and I'm reading all that and thinking - huh — that's not my world? Why is that not my world? So either the world has been lying to me...or you have. (Gunderson 12)

The texts NAN mentions became important source materials for defining the character's newly found point of view. Reading as much of these source materials as time would allow provided a tangible relation to NAN's word choices within the text, perspective, and developing her psyche. NAN often references theoretical points made in The Second Sex so it was important to define what these sayings meant to myself as the actor in a personal way. Doing this provided an avenue to decipher their impact on the character. In The Second Sex Simone de Beauvoir writes, To be present in the world implies strictly that there exists a body which is at once a material thing in the world and a point of view toward this world, but nothing requires that this body have this or that particular structure. (7)

This quote provided the motivation and support for NAN's outburst at the beginning of Scene Five. SIMON has just freed NAN from KYLE's mental entrapment during the flashback to their 
courtship. After "coming to" she is physically fed up with KYLE's manipulation, and as mentioned previously, the decision was carried out to have NAN pack her belongings. KYLE. You can't blame me for the way the world works. You can't blame me for life and biology. You can't do it. So I don't care what magazine you read, or where you think you can go to make the world any different, or Jesus or Jimmy Carter would do -but I am NOT the BAD GUY. I am JUST A GUY. And GUYS are different than GIRLS. SIMON. (With pompom.) Insight.

KYLE. And we get madder and pushier then y'all, and it's not our fault! Power and muscle were given to us! Sexiness and cooking skills were given to you! It's the way my daddy did things and it's the way most of the goddamn world does things.

SIMON. Nono, keep going. This is great.

NAN. KYLE.

KYLE. Fuck you.

NAN. KYLE

KYLE. You're a dumb, stupid girl.

NAN. Biological determinism has no effect on me, KYLE. (Gunderson 48-49) Through the writings of de Beauvoir NAN sees herself as an equal, she embraces that she isn't anyone's property, and her sex organs do not determine her worth. Her frustration doesn't mount until KYLE continues to chastise her, and this carnal response leads NAN to leap towards KYLE in physical and verbal outbursts. 


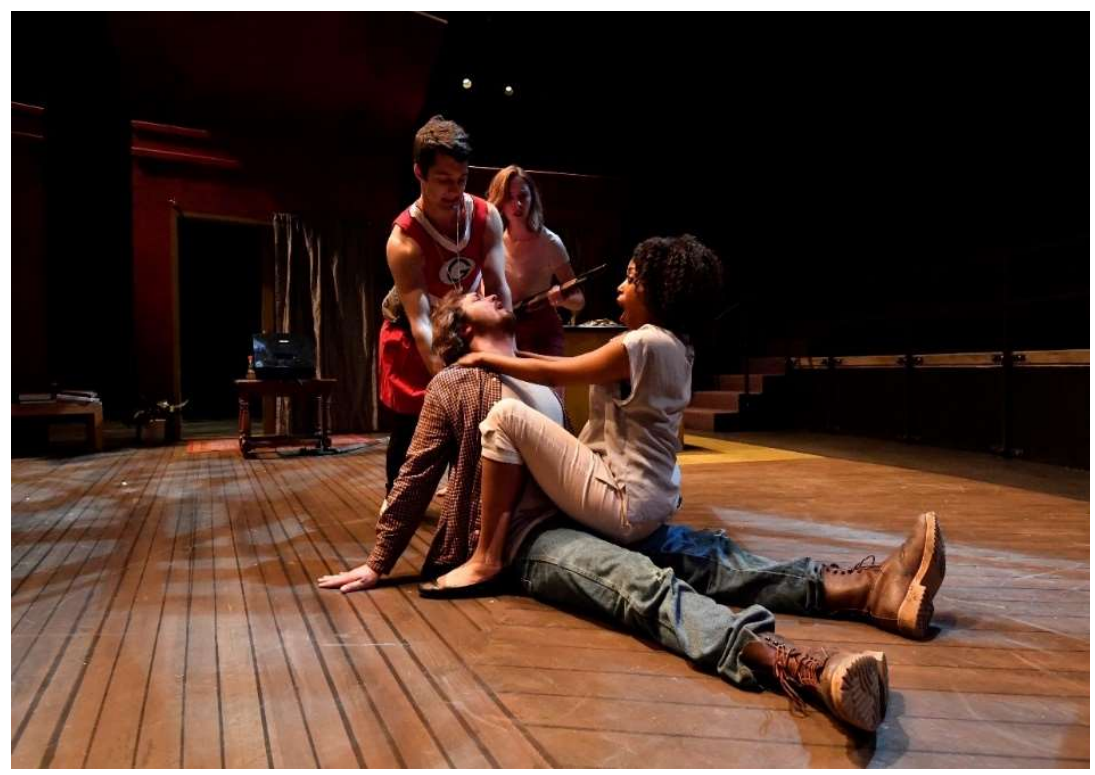

Fig. 6. Rehearsal photo; Simon (Hively) and SWEETHEART (Haley Hizer) free NAN (Rachelle) from KYLE's emotional entanglement at the end of Scene Four (Gay).

Additionally, de Beauvoir's theories provide backstory to the revelation NAN must encounter prior to the show's start. In order for NAN to reach the level of vengeance which would call on the bears to feast upon her helpless husband's carcass laced in honey, de Beauvoir's words were imagined to lift off the page and directly call to NAN, telling her what is wrong with her world, “... both your mind without a body and immoral man are strictly inconceivable..." (de Beauvoir 7). This sketched NAN's dissatisfaction in her marriage and became the foundation for NAN's internal disharmony. NAN's backstory explored the comfort the character received by hearing an outsider identify the missteps in her marriage. de Beauvoir does not negate whether this machismo behavior exists. This constructed the viewpoint for NAN that essentially, she has been bamboozled. For example, in the flashback from Scene Four, young KYLE awkwardly proposes to the hopeful, young, naïve NAN.

KYLE. And I'm saying that I'm a way better guy with you than with-like-my guy. And. 
Since freshman year you were the best thing in my life. Even that summer at Daytona and all those hot girls were getting drunk and I didn't do nothin' cause I had you...in mind. And you are so pretty. And you're like this precious thing. And I want you to be mymy...thing. Like for life.

NAN. ....Penguins are for life. I saw this documentary, and they raise babies in the worst weather in the world, and they take turns getting fish, and they take care of each other their whole lives, and when they pair up and nozzle each other their little slopey heads make like, a heart.

KYLE. See. That's such a girl thing. And I need those kinda things...

(Suddenly he hugs her-like a small child would hug a mother-around the middle with his head on her chest. She hesitates—-then complete the picture—holding his head like she was protecting him.)

KYLE. I'm a fuck up sometimes. And I know I can't give you everything just yet, but I will. And sometimes I might need-like-space or...porn?

But more than anything I need you. And I wanted to ask your dad but-I went to the cemetery outta respect. And I promise the ring's comin'. If you'll...marry...me. (NAN smiles a big smile.) (Gunderson 44-45)

NAN agrees to this union. Their relationship standard is set by KYLE who promises to love her and provide. The Second Sex provides the understanding that KYLE is the one who has broken his end of their marital bargain. It informs the confusion in NAN on whether she should leave, and even her anger in what her relationship has become. The mental struggle in NAN is the desperation that KYLE will change, returning to the charming man she first met, de Beauvoir informed NAN's psyche that, 
But even the primitive societies that are not aware of the paternal generative role demand that woman have a husband, for the second reason why marriage is enjoined is that woman's function is also to satisfy a man's sexual needs and he take care of his household. These duties placed upon woman by society are regarded as a service rendered to her spouse: in return he is supposed to give her presents, or a marriage settlement, and to support her.... If she is maltreated treated or wronged, she has the right — more or less definitely guaranteed — of going back to her family and herself obtaining the separation or divorce. (Beauvoir 427)

The play, along with De Beauvoir, aids in constructing NAN's desire to be a dutiful wife, it is the verbal agreement of their marriage, and any union. NAN's understanding of what their marriage would be is articulated as, “... and when he is tired of such roaming, he gives himself a home, a fixed location, an anchorage in the world" (Beauvoir 430). Upon reading this NAN can reconcile with her plan. She isn't at fault for their marriage's failure, but it is KYLE that has failed. NAN can now embrace her innocence as victim. She has done all these things, served as a doting wife by cooking, cleaning, and slaying deer meat on command, but the decision to leave is cemented in the moment NAN realizes KYLE doesn't need her anymore, because he will not become these things, and he hasn't been her protector for a long time. 


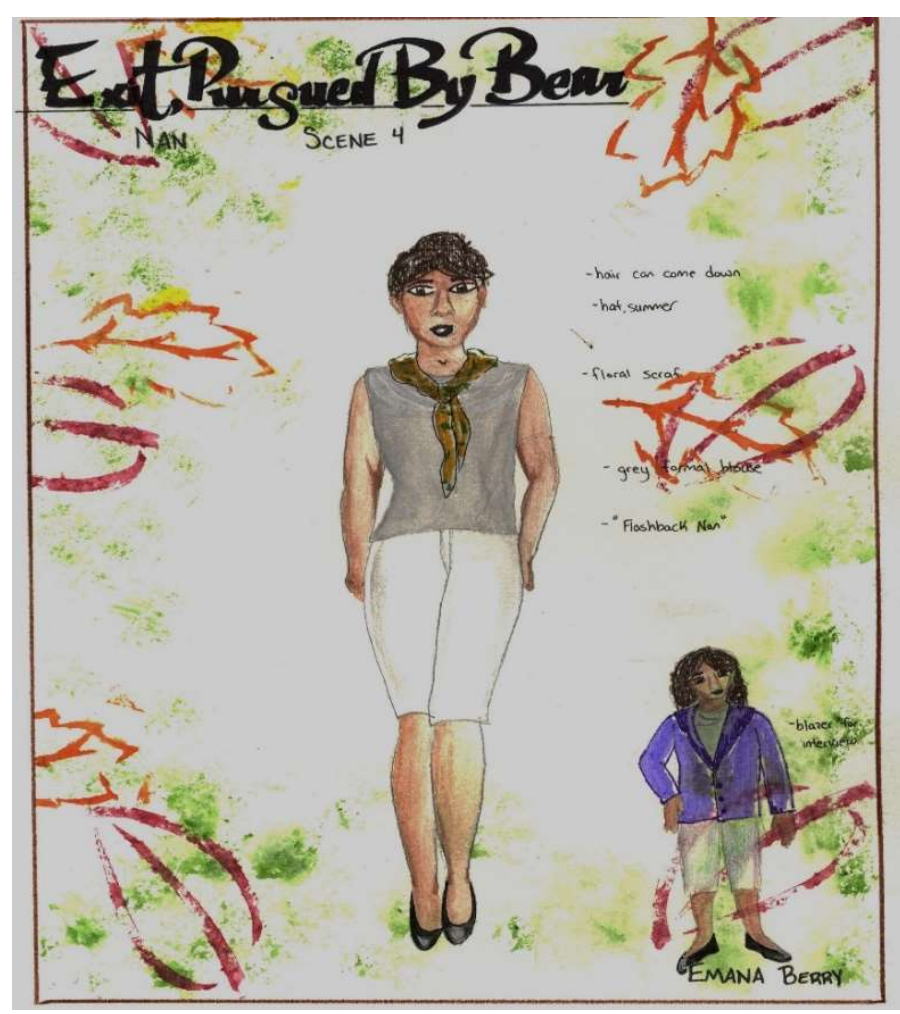

Fig. 7. Costume rendering; NAN embraces her free will by letting her hair down by the play's end.

Please Move, You're in My Way

While a play may provide many helpful clues to create your character's point of view, the actor may encounter other references that challenge, or block an actor's accessibility in connection with their character. This occurs when an actor's research is in conflict with who they are personally and interferes with their ability to build a character's dimensionality. This challenge developed from NAN's frequent references and admiration of Jimmy Carter. In her closing monologue she even recites excerpts from his well-known crisis of confidence speech. (While they pack up, and finish the meat for NAN recites the following...

(Perhaps actual footage of the Carter's 79 crisis of confidence speech projects $-N A N$ and Jimmy speaking at once.)

NAN. I want to talk to you right now about a fundamental threat to American democracy. 
It is a crisis of confidence. (Gunderson 53-54)

Throughout the play NAN finds her strength in Jimmy Carter. While this is never fully explained, perhaps it is really an extension of the author's own Georgia roots, and Gunderson's personal connection to the $39^{\text {th }}$ president. It was difficult to find a cohesive thread to NAN's backstory in Carter, specifically because of her young age of 27 . This challenge was also a manifestation of my own Georgia roots as a self-identified Southern Belle. However, I realize that my perspective as a black woman from Atlanta does not connect with the world that Gunderson has constructed. For example, NAN is rural, I am urban, from the metropolis city limits of Atlanta Proper, NAN enjoys nature and animals, I do not-NAN is timid, and I have been described as intimidating. Therefore, it could be said that NAN is closer to the sensibilities of Gunderson herself, than me.

Regardless of the source, an actor's job is to be sensitive to the differing backgrounds than he or she, and to always serve the story. That does not mean the story will always serve the actor, or one will not face obstacles in this feat. A challenge I faced in building this character was embracing the clues which led me to believe this role was not intended for a black woman. This was seen in Gunderson's use of Carter. I am as much in tune with my Georgia heritage as Gunderson, but Carter is not someone that we praise in my household, or community. Please understand these are broad generalizations, and there are always exceptions to the rule, but there are other figures in Georgian history, specifically Atlanta that the black community identifies as heroes. Some of these men include Martin Luther King Jr., Maynard Jackson, Andrew Jackson, Hosea Williams and Congressman John Lewis to name a few. As a result, NAN's infatuation with Jimmy Carter seemed contrived. SIMON describes her fondness of him as, "You are a Jimmy Carter search engine, I swear" (Gunderson 37). 
NAN's admiration of Carter functions in the world of Absurdism because he is an unseen being, like Godot, in Waiting for Godot. Just like God, President Carter is this prominent figure in our society, and in the position of presidency designed to save the public. In contrast, instead of waiting like VLADIMIR and ESTRAGON, NAN stops waiting and decides to save herself, but if it weren't for Carter's influence in her life she would be unable to complete this task. Carter's speeches were helpful in defining the dialect for the Georgia Mountains, and were initially an attempt to experience and capture his charisma, or what made him charismatic at that time, but there was no visceral response. Unfortunately, the more research conducted on Carter affirmed comments I heard as a child that he was a weak, this interfered with the ability to connect NAN with him in a position of praise.

\section{How Racial Identity Got in the Way.}

Any researcher will experience road blocks and downfalls during their process of exploration. Results from data will not appear in support of an original hypothesis, interviews will not go as planned, and etc., but an actor must still tell the story in the manner which the playwright has written, this is not up for debate. To get over this hurdle I substituted NAN's Jimmy Carter, for my own. This substitution was necessary to construct the Jimmy Carter that Gunderson wishes NAN to fawn over. In Lorrie Hull's book, Strasberg's Method, she describes Lee Strasberg's key training tools, sense memory and substitution.

Most teachers do not advocate living every situation in life that might have to be created on stage. Actors are encouraged to substitute their own truth for what is needed when performing....The reality of many acts, such as dying or murder, can never be created onstage go but a sense of their actually taking place is imparted to the audience by the 
actor's substitution of realities from his own life. He imaginatively uses his mental, physical, sensory and emotional resources. (Hull 41-42)

Because I did not relate to Jimmy Carter, I substituted my own admiration of Barack Obama. When NAN says,

NAN. I am NAN Carter. And I wish Jimmy Carter was my dad but he's not. (Gunderson 17)

As mentioned previously, this plea is symbolic of NAN's void of paternal love. In order to access her need I conducted a series of imagination exercises learned during my second semester of first year study in Sanford Meisner technique at West Virginia University. I successfully used the quote above to daydream about my internal desires in reference to paternal abandonment. What resulted was the ability to substitute my own personal abandonment issues for NAN's. It was important for me to then find a more ideal candidate than Carter to fill my own paternal abandonment issues. Finding a personal reference deepened the needs within NAN, which provided a greater connection to NAN's psyche of acceptance, and the want to nurture. The following is a journal entry from one of those daydream activities.

I dream about what it may have been like to have a dad, to have a man who picked me up and giggled, flew kites with me, blew raspberries on my tummy, show me what a real man would have been like, if he were here maybe I wouldn't have fallen in love with the first man to say he loves me, to hold me, or tell me I'm beautiful. If my dad had been there I wouldn't have been raised by a single mom, not trusting her, not listening to her, she is the only one who didn't abandon me. She's always been there for me. Then you came along, and I gave up my dream. I wanted something more, not to be trapped in a vet with cats, or an animal shelter. I love animals, they've always been my comfort, they've 
always been a special joy, my cats. My bunnies were my first friend, and I miss them. I gave up so much for you, and my baby I can't give him up for you too. My dad was dead when I arrived. I was told he hurt my mom, my mom never trusted men, and didn't want me to listen to you, she wanted me to go to the big city, to get away from these stale mountains, but I've been scared to leave here-to leave you. I'm not sure if I'm angry at you, or me, I gave you my virginity because I thought you were my forever. I was taught to be chaste, to value myself, so when we had sex I thought it meant to you as it did me. And so maybe I am a woman on edge, maybe I'm losing it. I don't want anyone to know I'm crazy but hurting instead. (Berry)

The daydream not only provided a specificity of character need but filled in the character's backstory based facts found in the text. For example, in Scene Two A, during the author's use of A-effect, in NAN's direct address to the audience, she says, ".....and to listen to my mom..."(Gunderson 17). This information fueled more specificity when conducting the daydream and created a three-dimensional point not only for NAN's father, but mother as well. While President Obama was an initial point of reference to substitute NAN's paternal need, after doing the daydream exercises it was no longer necessary. The specificity that resulted from the daydream fueled the character's emotional response to the absent parent, however, this would not have been achieved without the initial investigation of Strasberg's substitution exercise.

Additionally, NAN's psyche was developed through documentary research on the film, Women's Libbers. The initial purpose in this source material was the construction of NAN's definition of feminism. I found myself equally connected to the characters need to understand what women's empowerment looks like. Because of the uniqueness of this resource quotes from the film were used to define NAN's motivation and evolving psychology. 
"Women are prey"-Marylin French (BBC Four)

Journal Response. And that's why I'm tying KYLE up, that's why I want the bears to come, because I don't want to be his prey anymore, I want him to feel what it's like to be preyed upon, bastard. (Berry)

As the character progressed, the thoughts of NAN and myself became intertwined. While I found myself, the person, reacting to source materials, the line of demarcation became blurred. It was difficult to discern the voice of the person, the actor, and character.

What I am challenged by is how much of my race affects my storytelling, or connection to my research. Watching this documentary on feminism I want to hear the black woman's voice. Where is she [in this specific source material]? But that isn't this work, it's about the beating of women, women as prey. (Berry)

While I recognize my place in this artistic community is both directly and indirectly influenced by black feminists such as-bell hooks, Alice Walker, and Angela Davis to name a few, the voices of women of color were absent from the BBC Documentary, Women's Libbers. This heightened my awareness that my dark skin was not taken into consideration when Exit, Pursued by a Bear was created, and even more so when selected for the WVU season selection. While the documentary was informative, and the message provided NAN with the public acceptance of her plight as a disregarded woman, specifically with references like, "if you tell the truth of women's lives, women's lives have to change" (BBC Four), and "women's rights have changed, but we haven't had a revolution" (BBC Four). These quotes from feminist Marilyn French in the documentary became pertinent slogans in developing NAN, but there was a personal void in seeing women that resembled myself in the film. In response to French's need for a revolution one journal entry read, "So what's mine" (Berry)? 
While these documentaries addressed understanding NAN's psyche, its accessibility was limited. The source materials lacked a three-dimensional representation of women, for instance the main character followed in the Private Violence documentary wore a confederate flag during her interviews, and the only woman of color discussed in the film was absent due to being incarcerated after killing her abuser. I was angry that abused black women were absent from the storytelling, and it caused my empathy for the women presented to waiver. This was also fueled by frustration with the text, and the collaborative relationship between my performance colleagues as it relates to personal beliefs on race and politics, professionalism, experience, and preparedness in performance and rehearsals. To provide context, WVU graduate acting students and undergraduate actors work alongside one another in department mainstage directions. This dynamic can have a negative impact on the rehearsal process because of the differing levels of maturity. These challenging areas resulted in my own internal anguish and manifested as NAN's boiling anger. Because the rehearsal process became its own source material for differing American social and political points of view it was easy to access the fury when NAN (holding a chain saw and with blood smeared on her face and hands) says,

\section{(NAN gets a knife. Goes outside.}

\section{Bends over the deer and swiftly slices it's neck open.}

\section{Blood on her hands.}

She comes back in. Nod to SWEETHEART, who drops her act.

Real time.

NAN looks to KYLE.)

NAN. And that was when I had the idea to let nature in and get the hell out.

Cause, baby, we're all animals... and we're all wild (Gunderson 17). 


\section{(BLACKOUT.)}

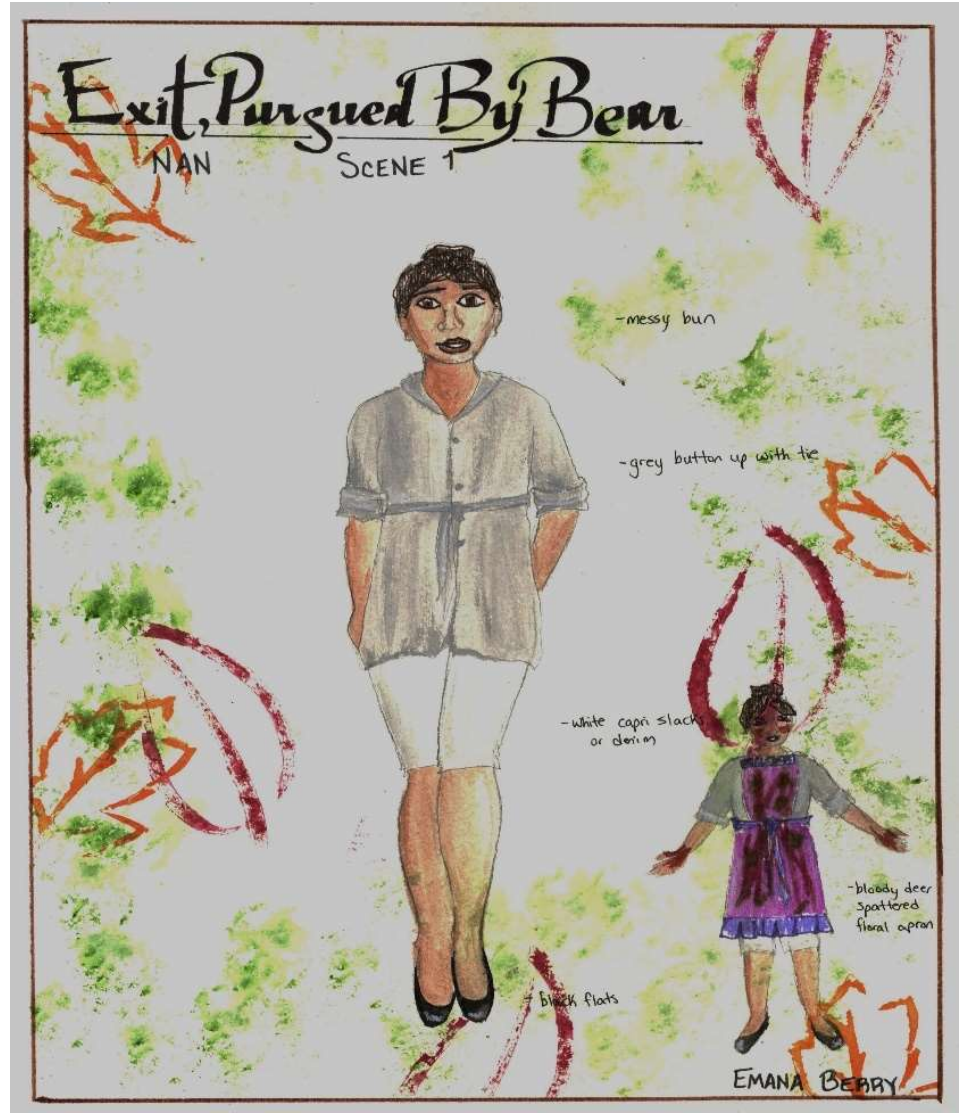

Fig. 8. Costume rendering; example of NAN's exterior change-she descends into a manipulative culprit the audience is hesitant to trust.

Inadvertently, the source materials further informed my own personal antagonism of the underrepresentation of black women as victims ignored by society's prejudice. Playing NAN provided the space to demystify those beliefs, but because it doesn't address the societal politics specific to the black female experience, and isn't designed to do so, the message falls flat in that regard. However, as mentioned on page 20 the representation of black bodies on stage affects the story. Race politics are continually present, and the actor's process to uncover these discrepancies will always be varied. 


\section{More on Process. Sample Journal Entries}

This section includes a collection of journal entries that discuss different methodologies, reflections, and the development of processes in constructing NAN.

Journal Entry \#1

Tonight was my fourth night of rehearsal with Exit so I have to recap the first night — it went really well! The read-through was positive, I connected with Ian, who plays KYLE, I was not, and I'm still not in agreeance with Cody, the actor playing SIMON, the choice for him to be Latino, because I don't feel like it serves the text. As an actor of color you are aware of the representation, or misrepresentation of other groups of color, and I am concerned regarding the representation of minorities in this particular instance, especially at a predominantly white institution. I understand that it's an opportunity to make a political statement about minorities in the era of Trump policy, but it doesn't serve the text which deals more with women's issues and takes a feminist's stance. I do however, think it would read better if the actor himself were Puerto Rican. This would layer the dynamic that this black woman, with a gay, Puerto Rican friend, is somehow trapped by traditional American ideals defined by white men.

But the good things, the good things are that I'm doing some of my best work in terms of flexibility. Instrument flexibility, especially in terms of the dialect. I have a better idea of my ear. It's picking up things, when I get it right, and when I get it wrong, I am aware of it.

I would like more time for character work. I know that will come, but I would like to have more of it in the rehearsal hall, we are doing physical blocking, but my character work is hollow, like point and shoot (Berry). 


\section{Journal \#4}

Laura, [my voice teacher, and the show's lead vocal coach, I served as assist vocal coach] came in yesterday. She led exercises for an hour, maybe an hour and a half long session on warm ups and the dialect. Afterwards all of the other ensemble members went right back to what they were doing. I've tried to send them enough sound samples for them to listen to. I get there 30 minutes early and do warm-ups, but no one comes. I incorporate some of the things I learned in London. breath work for 5 or 10 minutes, then phonation exercises, and then bringing in my resonators. I might even bring in some straws just to help the resonators to open up.

I'm a week behind schedule which is freaking me out. I've had some time to do some of the what if aka as if exercises in my head, taking moments from the script, personalizing them, and then journaling my responses. It helped me, but I'm still hitting the rut I normally hit where I'm actively connected, and things are working well, but when I get to the rehearsal hall it's not as fluid. That is frustrating me! When all else fails I'm learning to trust my talent, but this is still an area I'm seeking to improve, but the trust hasn't become habitual yet. Post-graduation I will continue to work with a one-onone coach to work through these emotional stumps. It's not that I don't have the emotional life, but when it's time for me to do it on stage, maybe because I add pressure it disappears.

I'm working on specifying "the doing," I've gone through and beat out pretty much all of my chunks, what I'm doing, but I haven't memorized them so I've got a lot of stuff going on in my head at one time. Where's my blocking? What am I doing to KYLE? What am I doing to SWEETHEART and SIMON? In the scenes with the four of us things get 
cluttered. Maybe I just need to work on specifying those things, but the scenes with me and Ian they feel good. I know what I'm doing, I forget about it and just live with him. Hopefully we get to work more soon.

The more comfortable I get with those scenes with the four of us I think I'll just be able to live. I am concerned about the baby scene. I talked to Irene about it last night because she wants me to be over-the-top, but I feel fake-so it's hard to get into a rhythm. I'm also noticing the challenge in working with younger actors, they often indicate, they like to touch onstage, or get up close and personal so I'm view pointing, not intentionally, but just to open things up and essentially get away from the touchy-feely action that's happening.

NAN is coming along, I don't have a specific gesture for her, and I don't have her body language yet. I need to do some reading of all three of those books I reference in the play; I need to add some stuff on pregnancy. I've already done domestic violence research, and I've started watching Thelma \& Louise. I can tell the play is influenced by Thelma \& Louise-these two women going crazy.

The HBO documentary on domestic violence was sad to watch. This one woman in particular was beaten so bad that blood capillaries in her eye were burst, he strangled her, beat her with a flashlight in front of her child, essentially kidnapped her, and drove her to California. It's so sad to see what someone can do to another person. The documentary was informative. It made me question whether these are circumstances similar to my character. How badly have I been beaten? I don't know how to answer that, has he beaten me so bad that I've had to go to the hospital? Or has he slapped me a couple times? He smacks me, he's dragged my hair because that's something we've added in the 
show, but how bad has it been? That's something else I need to add in my research in addition to pregnancy, because to be honest, I don't know the answer. I'm going to bring this up with Irene and talk to Ian about it too. I'm realizing how much of a collaborative effort this is. It makes me wonder the difference in the professional world. If I would've come in completely off book, then these are questions I would have been able to ask. I'm still working through, and asking them, but I think that's a very valid question, how bad has he beat me? If I can answer how bad he's beaten me that will solve some of the hiccups, or the two-dimensional, flat feeling I'm having in the first two scenes.

The director became upset yesterday because the blocking wasn't memorized, but we've been doing organic blocking, not setting things in stone, so it's challenging to work in a such a different way, activating the physical and mental memory simultaneously. Coming in off book may have solved this issue. However, this process is helping me define my directing style. I am learning things I need to deepen my performance, like table work. An actor cannot expect a professional director to provide table work, I've got to figure that out for myself, which is a challenge in Educational Theatre, how much of the process should mirror the professional world? However, as a director I welcome table work into my process, because once questions are figured out, the stakes will change.

\section{Journal Entry \#6}

Here's what I'm learning about my process-London has helped me have a better understanding of how to get the text in my body. The exercise of walking straight, then making sharp ninety degree turns at each new thought keeps the ideas fresh so they don't become stagnant. I'm learning to trust that I don't have to put something on it, it is 
difficult enough to be simple. This is a welcoming way to work and has aided in the development of my toolkit.

I'm still doing the "as if" exercise ${ }^{6}$ I read this in Meisner this past week and it helped. We've discussed this concept in class, but to help me better route that theory is his definition of particularization ${ }^{7}$. For example, finding a moment in my life that matches my relationship with KYLE. I don't have an abusive husband, but I do have an emotionally abusive dad that I've stood up to. Being able to pinpoint how that moment has helped me, but sometimes it isn't consistent. It's interesting because I expect there should be one way to live the moment, imaginary circumstances, and etc., but to access those memories with my dad I do Strasberg's sense memory. Meisner's imagination exercise, along with sense memory can sometimes feel stagnant. To keep those moments alive and to distract me from getting things right I apply molding, flying, and floating from Michael Chekhov. They've been fun to play with, especially when I'm working by myself, and I'm learning things about my character. In my research I've made it through the Jimmy Carter speech, which was rough as hell because God knows he's dry to listen to, and then the domestic violence documentary has helped me with the physicality of a domestic woman, but I want to experiment more. I reference a lot about deer, so I want to experiment with what her physical life is as a deer. I'm going to play around with that in my one-on-one time. Oh, the documentary on the Penguins, oh my God it's so sweet.

\footnotetext{
6 "But a particularization, an as if is....your personal example chosen from your experience or your imagination which emotionally clarifies cold material of the text." "You see, this is an area of acting which makes its demands entirely on your imagination." (Meisner and Longwell 138-139)

7 "That when you come up against a text that's cold to you, which doesn't mean anything because the circumstances are alien to you, you use particularization - another way to say that is 'as if' -to describe for yourself a situation that would bring you personally to the emotional place you need to be in for the sake of the scene." (Meisner and Longwell 138)
} 
Having that visceral experience watching the documentary and they are the cutest animals. I'm going to try and be present with that internal feeling tonight. If we start there in the run I won't have to put on how I feel about the Penguins because I have created a genuine feeling about them. When I think about the Penguins I'll allow myself to fly.

\section{Performance \& Reflection}

Pre-Show Ritual

After the research is complete it important to develop a sanctuary before entering the theatre space as the character. Some practitioners believe it isn't necessary to prepare for the emotional life, while others agree that stirring yourself to tears offstage does not guarantee the re-creation of them onstage. Additionally, while tears are regarded as a climax in the character, or good acting, they do not indicate an actor is fully connected to the work, or that they've adequately prepared for the role. However, after sifting through research, and analyzing the physical and mental life of a character, the most difficult part comes when you must throw it all away. Literally toss it in the trash and walk on stage. Through my three years of study I have developed a cohesive practice to enter the stage, to free my instrument and imagination. This ritual has evolved from my work on Exit, but the basic principles remain the same. The order of the exercises fluctuates depending on the day, my physical needs and the time allotted to complete them.

Beginning with the voice, the goal is to achieve vocal freedom and physical relaxation, below are techniques I use that are presented by Patsy Rodenburg and Kristin Linklater. These exercises have been taken out of context by the original authors and are not presented in order, this is not a comprehensive list of the exercises performed, but a sample of the pre-show ritual in current rotation. Some of exercises I perform were learned under the direction of Robert Price, 
Voice \& Speech Professor at the London Academy of Dramatic Art (LAMDA) and have been passed down, because I do not have these in theory books they are not listed, but it should be noted these are a major component of my work. Citations occur at the end of each section, the numerals listed have been added to fashion a structure.

Kristin Linklater, Freeing the Natural Voice.

1. Imagine that someone is pulling up a little by your fingertips, and allow your ribs to be stretched from above, up out of your waist...

2. ....Now let the weight of your head and neck hang off the top of your torso.

3. Feel the weight of your head dragging on the big vertebra that connects the neckspine to the body-spine...

4. ....Let your knees relax so that your weight remains over the middle of your feet.

5. ....Picture your torso hanging from your tailbone, giving in to the force of gravity.

6. ....Breathe easily. You are doing this to relax all the torso muscles, shoulder muscles, neck muscles, head and arms.

7. ....begin to build your spine up again, vertebra by vertebra, as though building a castle of nursery blocks one on top of the other. (Linklater 34-36)

\section{Pasty Rodenburg. The Actor Speaks.}

8. Neck and Head Position

- Let the head drop down until your chin touches your chest. Keep the jaw free. Using your hands, massage the back of your neck. As you do this don't tighten your shoulders.

- Swing head gently across the chest from one shoulder to the other.

- Lift your head until you feel it balanced on top of your spine.... 
- ....Gently rotate your head... (Rodenburg, The Actor Speaks 22)

9. Vocal Ladder ${ }^{8}$

10. House of Resonance 910

To free the imagination while achieving physical release, and movement of the breath the following exercises serve as my physical warm-up. What is listed references a partner, but I perform the exercises alone galloping forwards and then backwards in any section of the theatre that provides enough room. I was introduced to these exercises during an intensive study. I mimic the sounds of the drums with my voice — this awakens my vocal articulators simultaneously.

\section{Jackie Snow. Movement Training for Actors}

It is really important to encourage actors to travel through space with an arm swing; an actor can gallop across a room allowing the momentum of the swing to motivate the journey. When one plays with the expansiveness of movement and the ease with which the body moves through space, the expressive imagination reveals itself. (Snow 52)

\section{Forearms and backhand swing}

1. Stand on two feet...

2. Float your arm up, thinking of your golden cloak.

\footnotetext{
${ }^{8}$ To see sample exercises visit Chapters 14, 15, 16, 17 and 18 of Kristin Linklater's Freeing the Natural Voice, pages 245-293.

9"'In theory the whole body resonates the voice, but the most obvious and important resonators are in the chest, throat, face, nose and head. Each human resonator acts as an amplifier. The more resonators you use, the clearer your voice will be and easier it is both to sound and project the voice. Also, the more natural amplification you use, the easier it is to work in space. Always remember that one of the actor's functions is to fill space with presence and with voice." (Rodenburg 92-93)

${ }^{10}$ To see sample exercises to activate the resonators visit Chapter 16 in Kristin Linklater's Freeing the Natural Voice, pages 275-278.
} 
3. Gallop and swing simultaneously over and over and then turn back to back and repeat the movements, but 'backhanded,' as in a tennis stroke. So the swing goes: forehand, backhand, forehand, backhand.

4. Keep galloping and turning back on yourself as you swing. (Snow 64)

\section{Swinging both arms over, bending down and peeping through}

1. Face your partner, take both arms above your head and lean top right diagonal.

2. Swing under and back and under and back... using your upper torso, but go no lower than the waist.

3. Swing both arms over and over, keeping the body upright at this point, then bend over towards the bottom left-hand corner, peeping through on the second count of 'and one' as you are galloping, really using thighs, ankles and feet to propel you down the diagonal. (Snow 63)

Afterwards my imagination is free. I then outline personal objects throughout the theatre space that allow me to move without restriction in the space, i.e. if it is my home there is a certain level of comfort required. These needs change from production to production, but personalizing the space allows for greater relaxation when moving through the world of the play. Lee Strasberg calls this technique private moment ${ }^{11}$. I was first introduced to this concept under the study of Hope Arthur at the Lee Strasberg Institute in New York City. I expanded this concept during my first year of study at WVU, guest director Richard Garner presented this method as taught by Uta Hagen.

\footnotetext{
11 "The private moment exercise should enable the actor to develop a private kind of concentration, to engender via the exercise the sense of being unwatched. The ultimate value is that such a sense is portable and can be carried into actions, behavior, words and scenes unrelated to the actor's particular room. This portable privacy can be taken into any kind of scene, whether the actor is alone or with others, and the actor then is able to maintain a sense of privacy in front of the audience" (Hull 70). For a more detailed description and exercise examples see pages 68-74 of Lorrie Hull's Strasberg's Method.
} 
I always set up my secondary fourth wall exactly the way I would if I were to use it for a primary purpose. I finish the room, so to speak, by placing imaginary objects that are familiar to me, that have logic and are consistent to the place on that fourth wall of my other three walls, except that the objects are secondary in importance. I imaginatively place at least five or six objects across the back and sides of the auditorium, anchoring them to actual objects which exist there....My objects must be so particular that I can take them from my mind's eye and place them where I choose. (Don't try to turn an exit sign into a picture, but hang your picture on the exit sign!) I don't need to tell anyone what I am using. My objects are only there for me, for my privacy, for my freedom from audience intrusion. (Hagen and Frankel 109)

After moving through my body physically, vocally, and imaginatively my warm-up ritual ends with, breathing in the space. ${ }^{12}$ This centering exercise is sometimes coupled with selected thematic music that allows me to transition further into the world of the play.

\section{Moving On: Physical \& Emotional Freedom}

In the summer of 2015 I found myself in a hot, open, aired classroom with dingy, carpeted spring board floors. The room was filled with the smell of paint, emotions of anxiety, and tension. It sat nested along the back alleys of winding, cobble stone, Oxford, UK roads. What I learned in that room provided me with a foundation for a reliable pre-show and rehearsal ritual. It is now my guide to an effective physical warm up. This physical preparation led by Jackie Snow has been coupled with different vocal techniques learned under the tutelage of Laura Hitt

\footnotetext{
${ }^{12}$ If you are free in the breath and you breathe a space appropriately you will not only take in the breath required to fill the space but you will make contact with the space and its perimeters. You will inhabit and own the space along with the words you speak.... Whatever space you are performing in, stand on the stage when it's empty and breathe to the perimeters of the theatre or room. Not only to where the audience ends but the whole space from side to side, top to bottom. (Rodenburg $56-57$ )
} 
and Robert Price. What has resulted is greater freedom in my physical life as a human being, and subsequently as an actor; as well as that of my characters. My training over the last three years has constantly forced me to face the tensions that I hold in my body, be it from physical injury, or fear of failure in an unforgiving profession. These distractions have manifested as restrictions within the body. While much of my training has been designed to loosen these tensions, change these habits, and give me more autonomy, I have not been able to truly understand, and often struggle with the practicality, and success of these tools. As a result, I have been challenged by the task of creating a language that successfully connects the principles of theory and practice in my work as an actor.

\section{Beyond Physical Limits}

Journal Entry \#11

The show closed and-I don't know. I'm glad it closed, it was a good show. I don't think I told you, but I injured myself this week. I sprained my ankle during Tuesday's show. Ian lifted me up and when I came down my foot twisted on his boot (he shouldn't be wearing steel toe shoes and me ballet slippers, but I digress). As a result, the last four shows I had to wear a boot. Ironically, it works well with the storyline of domestic violence. The first night it worked exceptionally well because the cast fought to make sure the storytelling was clear. I've had to alter how I warm up because of the boot. It's too difficult to travel up and down the stairs so I stay in my dressing room. If I don't lead a warm-up it feels like the group simply decides not to do it and the show suffers. It is a physically and vocally demanding piece, you cannot afford short cuts, and it's a lot of weight to carry the success of the show on your back. 


\section{Journal Entry \#11 Continued— "What Did He Say?"}

On the last night of the show Brandon and I had an interesting conversation. He enjoyed the show, it was entertaining, fun, but this was not his favorite character, my characterization of a role. Of course, I hear, I didn't do a good job, but he says he didn't like the character, he felt like the character was flat, she lacked dimension. That made me think about what I want to talk about in my thesis-the struggle to specify character when a lot of information isn't given in the text, or to specify character in satire. I've never done satire, or Brecht (maybe that influenced why) Brandon did not feel the character was three dimensional, so maybe defining, "what is a three-dimensional character," "what is a two-dimensional character," "what basic text analysis/investigation will fill in the blanks for your character?" I filled in a lot of the physical life by studying deer, watching the documentary on women in domestically abusive relationships. What I would have liked to have done more was parade around doing those physical traits in rehearsal, or I studied them so fully that I didn't have to think about it. Patsy Rodenburg talks about the Second Circle ${ }^{1314}$, and my most successful attempt at that was Tuesday night when I sprained my ankle. I remember the night of my injury vividly- me, backstage doing swings and chanting, "I am an open channel," "I am an open channel." Then mulling over conversations with friends and colleagues, reminding myself I am good enough, and on that stage I am fighting for my life, and I did, maybe too much. I went with it, whatever was given to me onstage, and I gave it back. Whenever I felt myself getting in my head, I got out of it. Then I notice those things, i.e. crying on cue

\footnotetext{
13 The second circle is, "being present," "an exchange of energy," "being connected," "the give and take of being present," "the circle of survival" The circle of energy of absolute intimacy..." When you're really connected with your character and the other actor(s), everything else falls away (Rodenburg, "Second Circle").
} 
come more readily to Ian. Maybe it's what Irene said, in that last scene you feel like you have to make yourself cry because you're afraid of the scene, and that's so true! What tools should I do to get over that hump? I am an open channel, yes, but the last night, I got in my head although everything was going well.

Perhaps the answer is simple, confidence. I do the work, I work hard, I study, and I read. I would have liked to have read all of the Second Sex, Pride and Prejudice, the entire Jane Austen anthology, but you don't have that amount of time. Acting is about shortcut access tools to develop a character quickly, because sometimes there's not enough time to read it all. I'm emotional because I'm not feeling like I did enough, but I also must accept there isn't a plethora of time to create these characters. I'm frustrated. I don't know what the answer is, and those are the areas where I feel like I feel inadequate. I didn't cry every time, I look at other people that cry, and I want to achieve that. Maybe I have to do a full body warm up every time. I need to do it two hours before call, one hour for voice, then one hour for physical, then closing with laying on the floor and doing deep breathing, being confident, trusting I've done the work.

\section{Some of the Nitty Gritty}

Exit, Pursued by a Bear tested my stamina in more ways than expected. My initial interaction and response to the show was the drama. I'm funny, yes, I get that, but the drama is what speaks to me as an artist so I overlooked the humor at first read. Perhaps that's because I'm running from pieces of myself. Now, several months since closing things are clicking, light bulbs coming on, revelations about different methodologies that could have improved my connection, homework assignments I should've done, understanding what “doing” in Meisner terms really means, the list goes on. Yet, I realize how much of a gift the show was, I was challenged 
professionally, not just as an artist, but also in the conversations with my colleagues when we disagreed on politics, race, and social values. Please note, Exit alternated days in the rehearsal and performance space, it shared a stage manager, set, props and scenic designer with the repertory production, TopDog UnderDog. It was challenging to work without props, missing props, broken props, and alternating spaces. What was most eye opening, and hurtful was, for the first time in my career at West Virginia University I didn't feel supported by the department, not my professors, but the support of the production's technical logistics. This was new, and markedly different from the support I've seen in previous main-stage shows. To see my director not supported was disappointing. Many of my personal values came in to play. Do female directors face prejudice? Yes, out there, but to see her ideas about the technical needs she envisioned initially dismissed was unfortunate. Additionally, the scenic designer and props master, Imani Johnson, a woman of color, effectively executed the creation of two repertory sets and props, but from my point of view with limited, to no support of others in her discipline. As a result, we began rehearsal without props, and things trickled in throughout rehearsal. I began to question, have all women been overlooked? Are we being set up to fail? These questions were disheartening. Perhaps it was the simple fault of biting off more than one can chew as a department, the production team was shared for two prop and technically demanding shows; what resulted was lack of cohesiveness and confusion in the rehearsal hall. However, this chaos presented opportunities for new work and diversity in the season which was refreshing.

I am vocal, sometimes too much. It is challenging to balance being respectful and standing up for yourself. I often told my director, “don’t let them run over you,” or "you're too nice," and I meant that in terms of the production support, and even the cast. I found myself the only cast member willingly agreeing to more rehearsal time, telling my director we are expected to be 
here, and cast members trying to maneuver around that responsibility. I've worked with some cast members in previous productions and those attempts have not occurred in productions led by male faculty. Interestingly, performing a show which at its core is equality amongst the sexes, some of the parties involved had not allowed themselves to be affected. If we aren't affected, how then can we affect others?

\section{Conclusion}

After the work is done, the performance complete, the actor sets upon the greatest trial, letting go. Learning from your experience and opening to the possibilities the next role will bring is far more difficult than the immediate response the actor entangles herself in, what did I do wrong? Like the athlete the actor must analyze the footage to improve performance, but unlike a sport the actor's process is not videotaped, the performance shouldn't be, and those that are, are well choreographed. The method towards improvement, or expansion of technique, is a predicament within itself. Doing so activates the analytical mind which paralyzes carnal impulses.

This paper has presented the methods used to create the role of NAN, but more so it serves as its own resource on how to move forward. Viewing each chapter as a stage in the development of a character, exploring one stage longer than the other, depending on the role, is sovereign. This exploration is not always fluid, or concise, and will alter depending on the needs of the production. Regardless of the time spent in a phase, or chapter, mining these components as an anthropological study will create dexterity in accessing character, and define a fundamental toolkit for the actor. This toolkit is not fixed, but changes just as the actor/artist matures personally and professionally. 
In this process of character development, culminating in performance, and the analysis of process through written language, what resonates most is an intimate moment shared between Alby and myself. Seeing the frustration on my face when surrendering to NAN's adult temper tantrum in Scene Three, me desperately wanting to cry on cue in Scene Five, on a short break she pulled me to the side to say, and I paraphrase, sometimes we can force an emotion on a moment, and we get frustrated if it [crying] doesn't happen, but what we have to accept is that's not what this moment needs. It [the emotion] is not right at that time, and you have to trust that. Trust your technique, you have good technique, so even when you don't feel like you're hitting the mark, trust your technique (Alby).

That's the most comforting lesson in this conclusion. The simplicity of that message provides me with the encouragement I need to step out there, begin again, and move forward. The technique is always there, the research of time, character, circumstances, and genre are access points to character. However, they are not the final indication of preparedness. Instead they are methods to reach greater freedom to embrace the idea that the performance is not final. Each night is simply the beginning, an exploration of research. Just as plays capture brief moments in time, a performance encapsulates a moment in your life as that character, and the moment is always in motion. Tomorrow the moment may be different, and that's okay, it should be, and that is welcoming. Irrespective, the technique has never left. The playwright, director, text analysis, and actor's process are the building blocks to assist us in achieving the ultimate freedom of play. They are supportive methods to enhance our techniques pliability. When all else fails the technique is still there waiting to guide you to walk upright. Assisting the actor to embrace the physical impulses she strives tirelessly to free at home, in the rehearsal hall, and on stage. 


\section{Works Cited}

*---. “Jimmy Carter. Crisis of Confidence.” YouTube, uploaded by 235pics, 23 Mar. 2010, https.//www.youtube.com/watch?v=KCOd-qWZB_g.

*60 Minutes. "12/11/1977: The First Lady.” YouTube, uploaded by CBS News, 9 Nov 2010, https://www.youtube.com/watch?v=KA6Zx479tD0\&list=PLFqgMYUbznZlYUgSFcg19CZFgWYqT1GF\&index=6.

*Carter, Jimmy. "Excerpt from Governor Jimmy Carter's Inaugural Address (Carter Center).” YouTube, uploaded by The Carter Center, 26 May 2011, https:/www.youtube.com/watch?v=FpXSf_1H2iw\&t=0s\&list=PLFqgMYUbznZlYUgSFcg19CZFgWYqT1GF\&index=1.

*Georgia Public Broadcasting. “Georgia Public Broadcasting--’Lawmakers Flashbacks“-January 12, 1971.”YouTube, uploaded by Mike Stroud, 3 Feb 2015, https:/www.youtube.com/watch?v=V1J_Bzl_I0s\&list=PLFqgMYUbznZlYUgSFcg19CZFgWYqT1GF\&index=3.

*PBS. “American Experience Jimmy Carter 1.” YouTube, uploaded by Lady Given, 7 October 2017, https.//www.youtube.com/watch?v=Mwcup9fxn-4. Accessed .

*"The Question That Made President Jimmy Carter Blush | SuperSoul Sunday | Oprah Winfrey Network." YouTube, uploaded by OWN, 27 Sept 2015, https://www.youtube.com/watch?v=hCHd5Xn8hok\&index=8\&list=PLFqgMYUbznZlYUgSFcg19CZFgWYqT1GF.

*“The Secret to Jimmy and Rosalynn Carter's Nearly 70-Year Marriage| SuperSoul Sunday | Oprah Winfrey Network.” “'YouTube, uploaded by OWN, 23 Sep 2015, 
https://www.youtube.com/watch?v=_ZXiOT4-FzI\&list=PLFqgMY-

UbznZlYUgSFeg19CZFgWYqT1GF\&index=5.

Alby, Irene. Personal interview. 8 December 2017.

Bartelski, Chris. "Cabins and Carter and Bears (Oh My!)." American Theatre Magazine, July/August11, p. 27, 8c0d4064-a-62cb3a1a-ssites.googlegroups.com/site/exitbearplayresearch/home/TCG\%20exit\%20pursued.jpg?att achauth=ANoY7cpA-

31OUMaekEZ21oIYqcdeBLt3ZYQPZLIPeLSo2m4UNFL2BFNypQykC09syT8KUOnq1 yYdhbq0CckftthSdvayFsqPASDhNhR0XFW4LmAR1imjpZObW__RDCGYKiaqB3k0lzAsMklhulPTJF 35gUBtBnWin5Q1gwmKYnDEVoRFEIQI5vKqx87GaivQHKsEvCsymt07zqyj0tp7SLtP V9ViV7Bc2gq97tCZ17gIIV26ai_WE\%3D\&attredirects=0.

BBC Four. "Documentary on Women's Liberation Movement." YouTube, uploaded by vagabondways2, 27 June 2015 , https.//www.youtube.com/watch?v=EOsLjbpHV8M\&index=35\&t=0s\&list=PLFqgMYUbznZlYUgSFcg19CZFgWYqT1GF.

BBC. "Penguins of the Antarctic - Nature Documentary." YouTube, uploaded by Nature's Beauty, 9 Mar 2014, https://www.youtube.com/watch?v=y2gbMbzpaUk\&index=13\&list=PLFqgMYUbznZlYUgSFcg19CZFgWYqT1GF. Accessed .

Beauvoir, Simone De. The Second Sex. Vintage Books, 1989.

Berry, Imani. “Exit Pursued by a Bear Journal .” 2017.

Bruder, Melissa, et al. A Practical Handbook for the Actor. Vintage Books, 1986. 
"Bystander Effect." Psychology Today, www.psychologytoday.com/us/basics/bystander-effect. Cash, Justin. "Epic theatre Conventions." The Drama Teacher Resources For Those Who Love Drama, n.d., www.thedramateacher.com/Epic-theatre-conventions.

Chekhov, Michael. To the Actor on the technique of acting. Revised ed., Routledge, 2002.

ExitBearPlayResearch. Gunderson Lauren, sites.google.com/site/exitbearplayresearch/.

Gay, Joseph. Exit Rehearsal Photos. 2017, Private collection, Morgantown.

Gunderson Lauren. Exit, Pursued By A Bear. 2012. Playscripts, 2012.

Hagen, Uta, and Haskel Frankel. Respect for Acting. Wiley Publishing, 1973.

Heath, Malcolm, translator. Poetics. By Aristotle, Penguin Books, 1996.

Hecht, Werner. "The Development of Brecht's Theory of the Epic theatre, 1918-1933." The Tulane Drama Review, vol. 6, no. 1, 1961, pp. 40-97. JSTOR, www.jstor.org.www.libproxy.wvu.edu/stable/1125006?seq=1\#page_scan_tab_contents. hooks, bell. Black Looks. race and representation. South End Press, 1992.

Hull, S. Loraine. Strasberg's Method As Taught by Lorrie Hull. A Practical Guide for Actors, Teachers and Directors. Ox Bow Publishing, ., .

Johnson, Imani. Bear Sketch. 2017, Private collection. Scenic design.

Linklater, Kristen. Freeing the Natural Voice. Imagery and art in the practice of voice and language. Drama Publishers, 2006.

McGonigle, Gerald. "Graduate Acting Studio 1.” West Virginia University, n.d., WVU College of Creative Arts, Morgantown.

Meisner, Sanford, and Dennis Longwell. Sanford Meisner on Acting. Vintage Books, 1987.

O’Neill, Mikayla. Renderings for Exit. 2017, Private collection, Morgantown. 
PBS. "The Private Life of Deer - Amazing Nature Documentary (HD).” YouTube, uploaded by Nature's Beauty, 27 Feb. 2014, youtube.com.

Pollack-Pelzner, Daniel . "You’ve Probably Never Heard of America’s Most Popular Playwright." The New Yorker, 16 October 2017, www.newyorker.com/books/pageturner/youve-probably-never-heard-of-americas-most-popular-playwright.

Rabin, Roni Caryn . "Nearly 1 in 5 Women in U.S. Survey Say They Have Been Sexually Assaulted.” The New York Times, 14 Dec. 2011, www.nytimes.com/2011/12/15/health/nearly-1-in-5-women-in-us-survey-report-sexualassault.html?ref=science). $\% \mathrm{E} 2 \% 80 \% 9 \mathrm{D}$.

Rodenburg, Patsy. "Patsy Rodenburg - The Second Circle." YouTube, uploaded by Michael Howard, 9 Oct. 2008, https.//www.youtube.com/watch?v=Ub27yeXKUTY.

---. "Patsy Rodenburg - Why I do Theatre.” YouTube, uploaded by Michael Howard, 9 Oct. 2008, https./Www.youtube.com/watch?v=L9jjhGq8pMM.

---. The Actor Speaks Voice and the Performer. Methuen Publishing, 2005.

Roose-Evans, James. Experimental Theatre from Stanislavsky to today. Universe Books, 1970.

Snow, Jackie. Movement Training for Actors. Methuen Drama, 2012.

The Complete Novels of Jane Austen. ed., The Modern Library, n.d.

Tran, Diep. “The Top 20 Most-Produced Playwrights of the 2017-18 Season.” American Theatre Magazine, 21 Sept. 2017, www.americantheatre.org/2017/09/21/the-top-20-mostproduced-playwrights-of-the-2017-18-season/.

Weekend Edition Sunday. “Examining Carter's 'Malaise Speech,' 30 Years Later .” NPR.org, 12 July 2009, https.//www.npr.org/templates/story/story.php?storyId=106508243. 
Weinhert-Kendt, Rob. “Lauren Gunderson on 'I and You,' a Play With an Explosive Twist.” The New York Times, 6 Jan 2016, www.nytimes.com/2016/01/10/theater/lauren-gundersonon-i-and-you-a-play-with-an-explosive-twist.html.

Willett, John, editor. Brecht on Theatre. The Development of an Aesthetic. 2nd ed., Hill and Wang, 1992.

Williamson, Joshua Blackmer. Photo of Nan tying up Kyle. 2017, Private collection, Morgantown. 